\title{
Performance analysis and modeling of parabolic trough based concentrated solar facility using different thermal fluid mediums
}

\author{
Ahmed Ullah*, Asim Mushtaq**, Rizwan Ahmed Qamar* and Zaeem Uddin Ali* \\ *Chemical Engineering Department, **Polymer and Petrochemical Engineering Department \\ NED University of Engineering \& Technology, Karachi, Sindh, Pakistan \\ **Corresponding Author: engrasimmushtaq@yahoo.com (A.Mushtaq)
}

Submitted: $17 / 09 / 2019$

Revised: $\quad 12 / 10 / 2020$

Accepted: $20 / 10 / 2020$

\begin{abstract}
The significance of sustainable power source has expanded because of environmental change and worldwide cautioning concerns because of its renewing quality. Solar energy is the focal point of numerous examinations due to modern industrial applications and small scale local applications in emerging nations. Solar energy is being bridled, either specifically utilizing photovoltaic or secondarily utilizing concentrated solar power. This study aims to design and fabricate a small scale concentrated solar power (CSP) plant using linear parabolic trough. Linear parabolic trough collector is used because of high efficiency and exceedingly prescribed kind of CSP. The scope of this study is to develop a CSP plant and also study the properties of various thermal fluids and expect the best transfer medium. The study done in this research is based on carrying out a detailed energy balance scheme for a linear parabolic trough collector while observing twenty-six vital design parameters, including the geometric measurements and material properties of concentrator and receiver pipe, thermal fluids properties, and operating conditions. Modeling of the system is carried out for different thermal fluids that are deemed viable for use. It was found that the results obtained from the fabricated parabolic trough CSP were used to verify the model and compare with the theoretical results. The conclusions deduced from this study will help design both small and large scale applications of linear parabolic troughs.
\end{abstract}

Keywords: Concentrated solar power plant; linear parabolic trough; thermal fluids; solar energy; parabolic trough.

\section{INTRODUCTION}

Even though photovoltaic solar technology is the most widely known today, the idea of concentrating solar radiations to utilize heat energy is found before the invention of photovoltaic solar technology. In around $200 \mathrm{BC}$, Archimedes ascribed the awareness of mirrors to concentrate the sun. A parabolic trough and the optical properties were studied by Diocles a Greek mathematician in the second century BC (H. L. Zhang et al., 2013; K. Vignarooban et al., 2015).

As far as CSP is concerned, a more recent historical achievement was done in 1913 by Frank Schuman in Egypt. He successfully built a parabolic trough driven pumping system. Such small scale experiments continued until the realization of CSP in California as an actual Power Generation Industry (H. Price et al., 2002). Nine separate parabolic trough based 'Solar Electric Generating Systems' (SEGS) were constructed with a total installed capacity of 354 Megawatts, based on steam turbines for power generation (F. Agyenim et al., 2010). 
Many countries have started taking an interest in CSP projects and are considering it as a viable means of power generation. Countries such as Algeria, Egypt, Morocco, Israel, Australia, India, China, South Africa, Italy, Portugal, Malta, Greece, and Cyprus had all CSP projects, either in work or in the pipelines. India plans to install $20 \mathrm{GW}$ of combined CSP and PV capacity by 2022. Such an increased interest in CSP of the international community is due to the ever-increasing energy requirements and diminishing reserves. Pakistan is also facing these issues; therefore, it is about time that unconventional renewable energy systems such as CSP are studied for feasibility (S. Chu et al., 2012).

The configurations that are being deployed to concentrate the solar radiations in a CSP system are a parabolic trough, collector (PTC), central tower collector, dish collector, and linear Fresnel. Each of these types has certain advantages over each other, but ultimately the selection among them depends on many factors such as the scale of operation, budget constraints, and location of deployment. Even though all of these technologies are being pursued, parabolic trough collector (PTC) is the most widely used technology because of its efficiency and practicality (A. F. Garcia et al., 2010).

Figure 1 shows the parabolic trough collector (PTC) technology, in which the parabolic trough is used to distillate the sunlight on the absorber pipe to pass the heat absorbing medium. The thermal fluid is constantly circulated to reach the temperature up to $400^{\circ} \mathrm{C}$. Thus, this heated transfer fluid is utilized to produce steam by heating water to run the steam turbine. Concentrator, receiver pipe, HTF, and tracking of the sun are the key subsystems of a parabolic trough collector. The concentrator must be of the highest optical efficiency along with being light in weight as it will be mounted on a frame that has to rotate to track the sun. The receiver pipe is the essential part of a PTC system and must be optimized accordingly. The receiver pipe must be designed as such to reduce the losses. Circular pipes coated with chrome black are the most commonly used system. For better efficiency and fewer losses, these pipes may be enclosed in vacuumated glass tubes. Heat transfer fluid must be selected based on its thermal properties. Due to inconsistency in the solar radiations, a storage system for HTF is also required. Lastly, a solar tracking system and a rotating mechanism for the trough are required (A. F. Garcia et al., 2010).

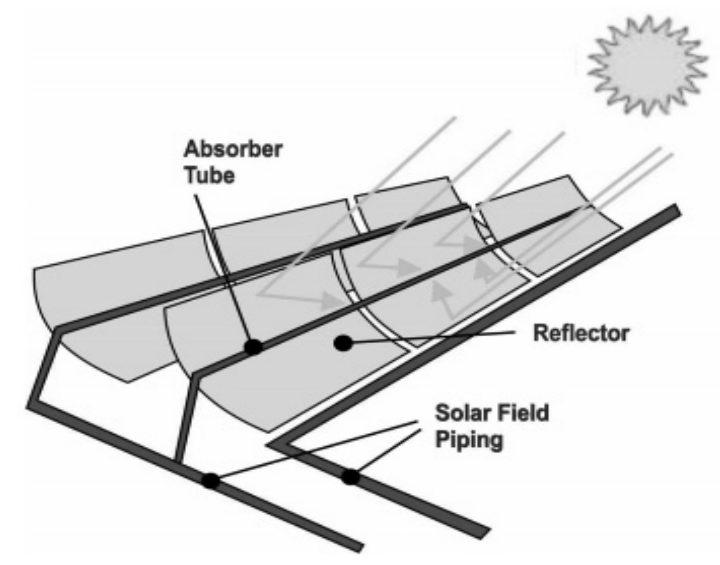

Figure 1. Parabolic trough collector (PTC).

A central tower collector framework includes a centrally mounted tower receiver encompassed by group of heliostats as displayed in Figure 2. These heliostats concentrate the sunlight onto the receiver. This permits highefficiency energy exchange at a solitary substantial collector point. High concentration proportions are accomplished in contrast to linear directing systems and enable thermal receivers to work at high temperatures with reduced losses. The receiver absorbs the sunlight from the heliostats and transfers the energy to a circulating fluid, generally molten salt. It transfers energy at $250^{\circ} \mathrm{C}$ to the saturated steam system. The steam at that point energizes a conventional turbine at the base of the tower (M. Ouagued et al., 2012). 


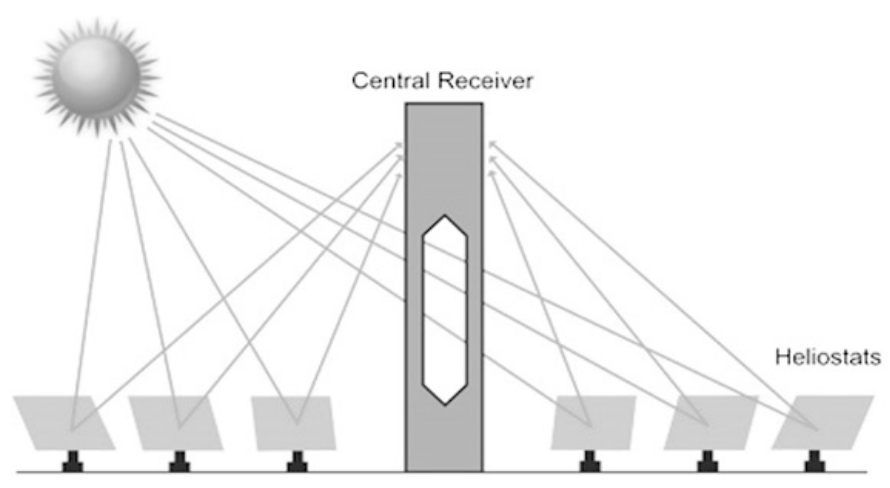

Figure 2. Central tower collector.

A dish sterling collector system utilizes a very different innovation than other concentrating advancements. A sterling engine is driven by the heat from the sun, which generates electricity. The principle parts of this framework are a parabolic concentrator and a receiver shaped solar light as shown in Figure 3. The concentrator is a high reflective mirror dish. The sunlight (800 times normal) warms a functioning fluid interacting with the receiver to around $650^{\circ} \mathrm{C}$. The thermal vitality affects the cylinder piston engine to equivocate backward and forward at 50 to 60 cycles in a second. The piston changes a magnet forward and backward in a coil of wire and produces AC current. The air-cooled engine is utilizing a radiator and a shut water-based coolant framework (M. Ouagued et al., 2012).

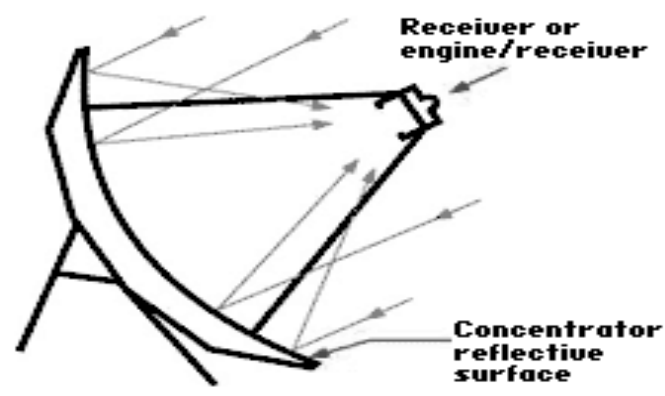

Figure 3. Sterling dish collector.

The linear Fresnel collector technology uses modular flat reflectors to emphasize the heat of sun onto high receivers that comprise a structure of tubes over which water flows as shown in Figure 4. The concentrated sunlight heats the water in the tubes, producing high-pressure steam in power generation. This steam application is directly used in industries (R. V. Padilla et al., 2011). The most frequent issue faced today by researchers is the selection of HTF and concentrated solar power (CSP) plant. The thermal fluids used today consist of thermal and synthetic oils, molten salts, and glycerol-based, which can heat transfer effectively.

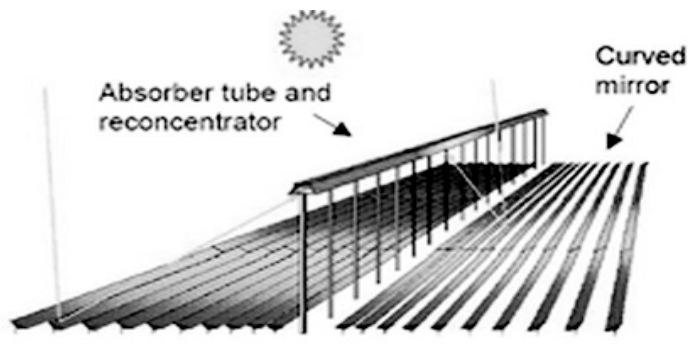

Figure 4. Linear Fresnel collector 
Although the process selected for these HTFs is rather obscure, usually availability and cost are the factors on which this selection is made. The selection of HTF, ignoring many critical factors and only focusing on cost and availability, may result in inefficient CSP systems. The most optimistic CSP industrial expansion estimations predict that seven percent of the power supply in 2030 might be engendered with CSP technology, which may grow more to a possible share of twenty five percent till 2050. Therefore, the need for thorough studies focused on the selection criteria of heat transfer fluid for CSP systems is a need of the hour. Previous studies would recognize the influences that are based upon the selection of a heat transfer fluid. A proper HTF selection system may also be developed, hence providing the CSP system developers with an optimized solution to the problem.

The objectives of this study include designing a small-scale linear PTC type CSP, developing a mathematical model for the heat transfer occurring at the receiver pipe, through which the HTF will flow, obtaining and comparing the theoretical HTF outlet temperature by solving the mathematical model for different thermal fluids, analyzing the results by different statistical techniques to predict the best heat absorbent HTF, selecting HTF for the experimental runs after the initial test run on water, analyzing the results and proposing the factors on which the HTF selection must be based and comparing the experimental and theoretical results, and optimizing the system for better accuracies and fewer losses.

The scope of this study is to increase the demand for green energy with lower carbon footprint and enhance the quality of the environment, advancing the necessity for a sustainable origin of clean energy. Sun is an abundant and clean source of energy for the world. Solar energy engineering is concerned with the conservation of this plentiful and enormous source. So, it is the best alternative solution to the recent energy problem. Being solar energy systems, concentrated systems have more potential with consuming less land area, capital, and operation cost. The parabolic trough system has capabilities in this particular field. This study is a precise energy model to estimate real-world results that could be obtained from domestic and industrial scale PTC. Also, the generation of code on user-friendly software like Engineering Equation Solver (EES) reduces the human effort of solving the complex energy model precisely with an increased number of iterations. Finally, building a generalized correlation for the parabolic trough justifies the need for time-saving alternative to estimate the total heat gain in PTC.

Optimization of the equipment design with the preservation of quality standards that results in lower cost is also an undertaken constraint of our study. Therefore, our design incorporates the use of polished films of aluminum and stainless steel in place of a heavy, fragile, and expensive glass mirror. Replacing the heavy and costly frame design with the lighter durable frame is also a part of our study. As far as the layout is concerned, modularity is the specialty of parabolic troughs. Modularity results in maximum utilization of area with an increased number of troughs, as the design includes a series of arrangements of two modular troughs. Finally, besides power generation, the parabolic trough can be efficiently used in all types of industries as the requirement of heat for all kinds of process is well understood. There can be enormous applications associated with this work including, but not limited to, the designing and simulation of indirect or direct steam generation systems, process heating, space heating, solar-assisted power generation, refrigeration, desalination, and cooling.

Concentrated solar power (CSP) plant facility is a major breakthrough in the area of solar engineering. It provides energy by utilizing heat radiations from the sun. The concerned type of CSP facility with this study is parabolic trough collectors (PTC). PTC has been used since 1870, when a Swedish engineer, John Ericsson, was able to successfully experiment with the PTC producing steam by direct steam generation (DSG) (A. F. Garcia et al., 2010). Since then, PTC systems have been upgraded with new researches in the field of solar engineering and CSP technology. Notable work in the field of PTC plant includes the use of heat transfer fluids like thermal oils for the maximum absorbance of heat, tracking systems to align the sun perpendicular to the parabolic trough surface for maximum direct normal irradiance (DNI) concentration, and the use of glass sleeve to reduce the convective losses to the atmosphere. The application of PTC system is not limited to power plant, but also for other purposes such as domestic hot water, air conditioning, pumping irrigation water by converting heat into mechanical work, and desalination.

Duffie, J \& Beckman, W provide fundamental literature on most of the solar technologies, also known as "The Bible of Solar Engineering" (S. Chu et al., 2012). In most of the heat transfer analyses, optical and material studies have been obtained from this book, as well as NREL's report, which studies different standard designs of solar parabolic 
troughs and its efficiency. NREL report by Forristall R. (2003) also published a mathematic model on the receiver pipe of the parabolic trough, which is later transformed into a computer program (EES) to provide effective results (C. K. Ho et al., 2014). Such work has inspired many authors in the field of solar engineering to study various characteristics of the solar power plant.

Ho C. et al. provided different methods of applying such statistical analysis (C. K. Ho et al., 2014). Roesle M. et al. described heat loss from parabolic trough receiver by developing a similar model as NREL and applying the probabilistic approach for generating a regression equation to calculate efficiency (R. V. Padilla et al., 2011). He used the Monte Carlo technique to generate random conditions to simulate his work. Continuing his work, Zaversky et al. presented a study that provided a statistical approach to analyze the mathematical model and used the Latin Hypercube sampling method to generate random conditions. This literature convoluted the uncertainty and sensitivity analysis upon the input variables, which measured the efficiency of the parabolic trough (F. Zaversky et al., 2012).

Zhang et al. and Cheng et al. studied the heat characteristics of a parabolic trough and design methodology and simulated their PTC using thermal fluid Syltherm 800 (H. L. Zhang et al., 2013; Z. D. Cheng et al., 2010). The results were verified from the results of Dudley V. (1994), who conducted a series of simulations and experimentations on PTC systems using the same fluid (C. K. Ho et al., 2011; A. A. Hachicha et al., 2013). Ouagued et al. conducted a study of five thermal oils, simulating them using NREL's heat transfer analysis and FORTRAN computer software. Different graphs were established showing the relationship of fluids thermal gain concerning different weather conditions and locations. It also simulated the fluid thermal gain throughout the year (A. A. Hachicha et al., 2013).

For the use of thermal oils and verification of heat transfer model, reports of Sandia testing laboratories provided experimental results that can be compared with the theoretical model of a PTC system. The study conducted in this report takes inspiration from the remarkable work done, as mentioned above. A heat transfer model similar to NREL's model is used, converting the mathematical model to a computer program to, then, calculate outlet temperature. The probabilistic approach has been applied to predict the behavior of the input variables and properties of the material related to the PTC system. The significance of such variables and properties is determined using sensitivity analysis. At last, different thermal fluids are simulated to calculate the best absorbing fluid.

\section{METHODOLOGY AND EQUIPMENT DESIGN}

The geometry of the concentrator must be studied to design the parabolic trough concentrator. The job of the parabola in sun powered concentrators is to center parallel radiation to a point in a good way from its vertex. The parabola is a two-dimensional bend that gives the cross-sectional form of a trough-formed straight concentrator.

The concentration tells us the amount of concentration achieved by a given concentrator. Geometrically, the concentration ratio $\left(C R_{g}\right)$ may be described as the collector aperture area $A_{a}$ divided by the receiver surface area $A_{r}$ as given in

$$
C R_{g}=\frac{A_{a}}{A_{r}}
$$

The rim angle $\varphi_{R}$ is the angle between the axis and a line from the concentration to the physical edge of the concentrator. Together, the central length and edge point of a parabolic concentrator totally explain its cross-sectional geometry. The rim angle is mathematically defined by (C. K. Ho et al., 2014)

$$
\tan \varphi_{R}=\frac{W / 2}{f-z_{R}}=\frac{4 f W / 2}{4 f^{2}-(W / 2)^{2}}
$$

where $W=$ width and $z_{R}=$ parabola depth at the rim.

Rim angle must be optimized to know the position at which the receiver pipe will be placed, as shown in Figure 5. Consider a receiver pipe placed at a rim angle $\phi_{R}$ and with a diameter

$$
d=2 r \sin \theta_{s}
$$




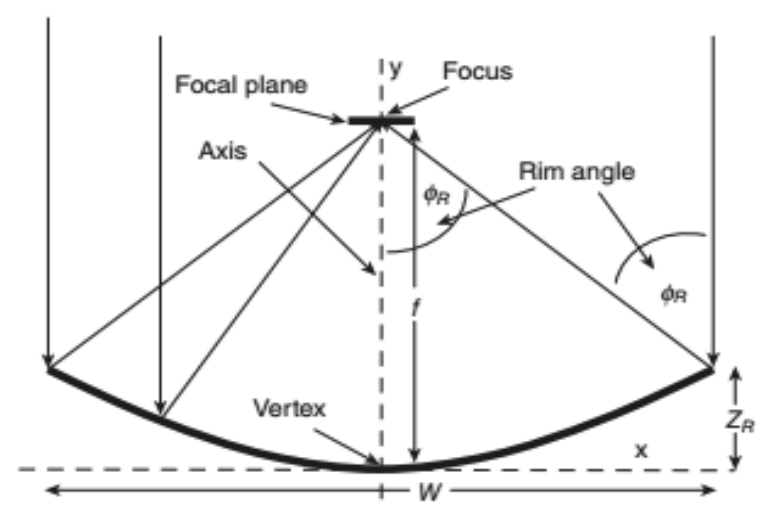

Figure 5. PTC rim angle.

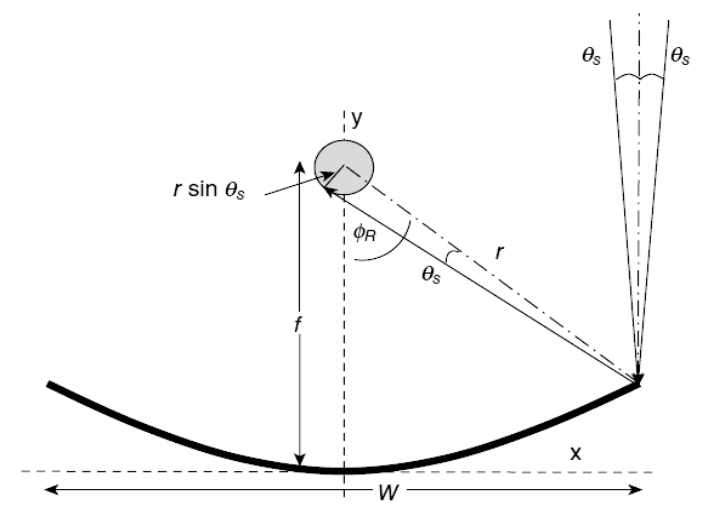

Figure 6. Optimization of rim angle.

The radius of receiver $=\mathrm{r} \sin \theta_{\mathrm{s}}$

$\sin \emptyset_{R}=\frac{W / 2}{r}$

$C_{g}=\frac{A_{c}}{A_{R}}=\frac{L W}{L 2 \pi r \sin \theta_{s}}=\frac{\sin \emptyset_{R}}{\pi \sin \theta_{s}}$

Differentiating $\mathrm{C}_{\mathrm{g}}$ w.r.t. $\emptyset_{R}$

$\frac{d C_{g}}{d \emptyset_{R}}=0=\frac{\cos \emptyset_{R}}{\pi \sin \theta_{s}}$

$\operatorname{Cos} \emptyset_{R}=0$

$\emptyset_{R}=90^{\circ}$

Figure 6 shows that the optimum rim angle for a parabolic trough with a circular pipe receiver is $90^{\circ}$. The parameters involved in the calculation of focal length and arc length are as follows: $s$ is the arc length, $d$ is the diameter or aperture width, $\varphi$ denotes the rim angle, $h$ is the height (from top to vertex), and $f$ is the focus (vertex to focal point) as given in Figure 7 (M. Fenot et al., 2011). 


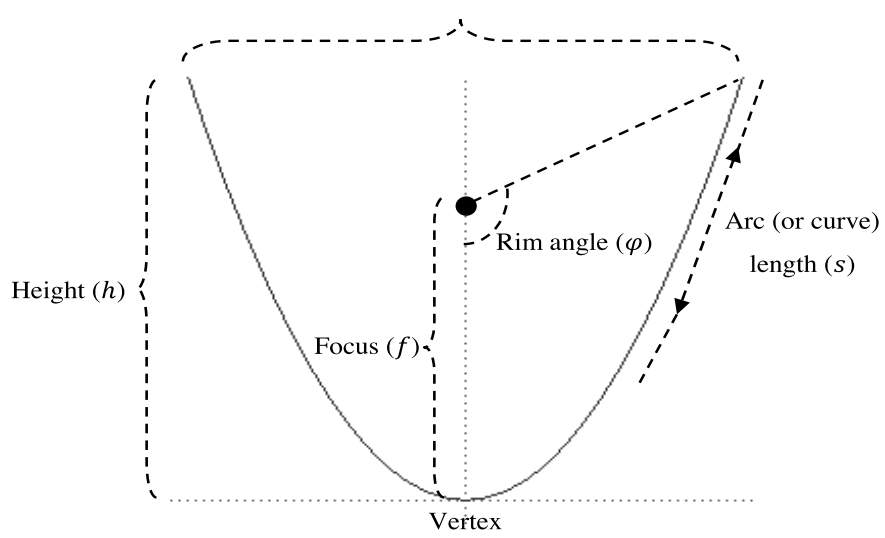

Figure 7. Calculations of the dimensions of the parabola

Eq. (4) can be obtained from the geometric analysis of Figure 7 (M. Fenot et al., 2011).

$\frac{s}{d}=\frac{1}{2}\left[\sqrt{\tan ^{2}\left(\frac{\varphi}{2}\right)+1}+\frac{1}{\tan \left(\frac{\varphi}{2}\right)} \ln \left\{\tan \left(\frac{\varphi}{2}\right)+\sqrt{\tan ^{2}\left(\frac{\varphi}{2}\right)+1}\right\}\right]$

$h=\frac{d}{4} \tan \left(\frac{\varphi}{2}\right)$

$f=\frac{d}{4} \frac{1}{\tan \left(\frac{\varphi}{2}\right)}$

By combining Eq. (5), moreover, Eq. (6),

$h=f \tan ^{2}\left(\frac{\varphi}{2}\right)=\frac{d^{2}}{16 f}$

Using the above relations, calculate width, focus, and rim angle of the parabola as given in Table 1 .

Table 1. Calculation for width, focus, and rim angle of the parabola.

\begin{tabular}{|c|c|c|c|c|}
\hline Application & Rim angle $(\boldsymbol{\varphi})$ & $\boldsymbol{s} / \boldsymbol{d}$ ratio & Height $(\boldsymbol{h})$ & Focus $(\boldsymbol{f})$ \\
\hline Circular receiver & $90^{\circ}$ & 1.1478 & $d / 4$ or $f$ & $d / 4$ or $h$ \\
\hline
\end{tabular}

The experimental setup consists of a few apparatuses combined to form a concentrating solar plant. These apparatuses are two parabolic trough collectors (frame and aluminum sheet), a pump, and a heat exchanging metal tank, as shown in Figures 8 and 9. Two parabolic frames are built using iron bars, which act as ribs on which an aluminum sheet is mounted. The aluminum sheet is $8 \times 4$ feet in dimension. When the sheet is mounted on the frame, the width of the parabolic collector becomes 3.485 feet, while the length of trough remains 8 feet. Two stainless steel pipes of length 8 feet each are held at the focus of the parabolic trough on which the DNI is concentrated and absorbed by the pipes. Inlet and outlet valves are provided to fill the pipe with HTFs and to drain them, respectively. The two absorber pipes are connected using a flexible hose, which can bear high temperature and also provides ease of movement of the trough for sun tracking purposes. 


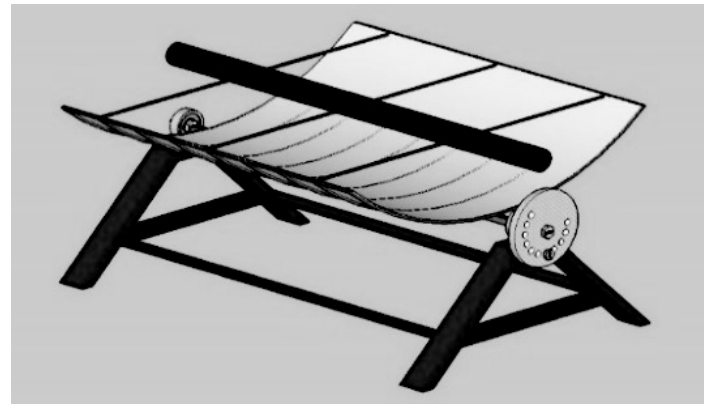

Figure 8. Fabricated PTC design.

A pump of $0.5 \mathrm{HP}$ is used to circulate the heat transfer fluid in a closed-loop. A metal tank is used to exchange the heat between heat transfer fluid and water inside the tank. The tank, with dimensions of $18 \times 18 \times 11$ inches, is filled with water. Two flanges on two sides of the tank allow 28 copper tubes of length 18 inches each to carry HTF, which has been heated by the parabolic trough collector in the absorber pipe to transfer its heat to the water in the tank. The heat exchanging action takes place in a closed-loop as the HTF is recirculated through the pump and reused to heat the water in the tank for maximum heat gain.

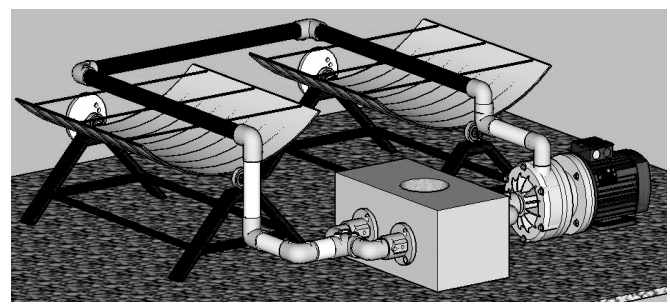

Figure 9. PTC system.

\section{Analytical Model (With Glass Sleeve)}

Figure 10 portraits the PTC comprised of a parabolic trough reflector, an absorber pipe, and a glass envelope. Solar radiations occur radially on the absorber pipe and are subsequently reflected from the parabolic trough reflector. The HTF temperature increases when it passes through the absorber pipe. Figure 11 demonstrated the various dimensions of PTC. Table 2 represents the heat flux description (M. Roesle et al., 2012).

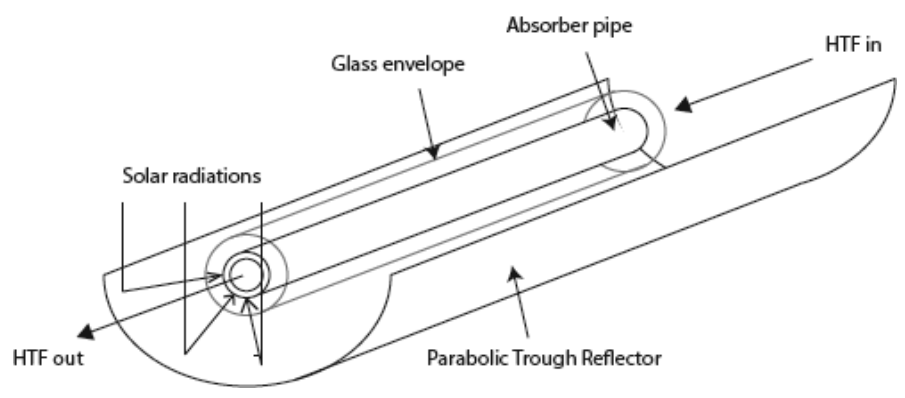

Figure 10. Solar parabolic trough collector. 


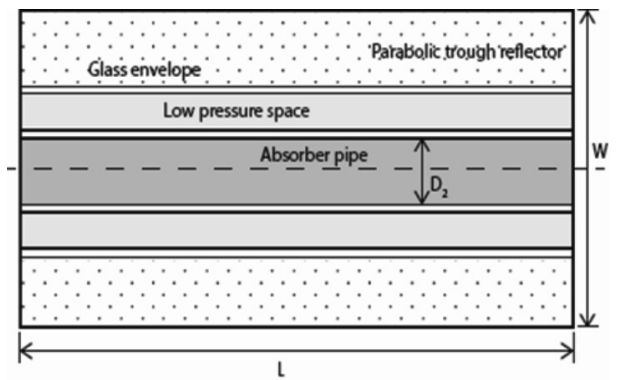

(a)

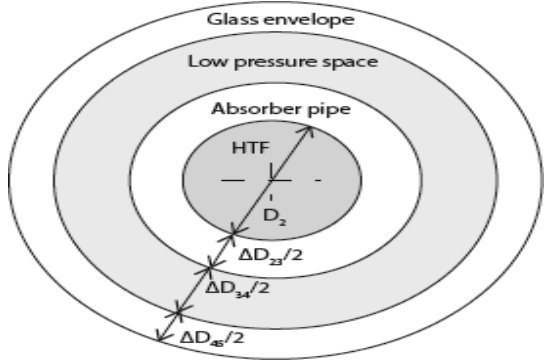

(b)

Figure 11. Dimensions of parabolic trough collector and absorber pipe.

Table 2. Heat flux description.

\begin{tabular}{|c|c|c|c|}
\hline \multirow{2}{*}{$\begin{array}{c}\text { Heat Flux } \\
\text { (Watt) }\end{array}$} & Heat Transfer Mode & \multicolumn{2}{|c|}{ Heat Transfer Path } \\
\cline { 3 - 4 } & & Trom & To \\
\hline$q_{5 \text { solenv }}$ & Solar irradiation absorption & Incident solar irradiation & Outer glass envelope \\
\hline$q_{3 \text { solabs }}$ & Solar irradiation absorption & Incident solar irradiation & Outer absorber pipe \\
\hline$q_{45 \mathrm{cnd}}$ & Conduction & Inner glass envelope & Outer glass envelope \\
\hline$q_{57 \mathrm{rad}}$ & Radiation & Outer glass envelope & Sky (atmosphere) \\
\hline$q_{56 \mathrm{cnv}}$ & Convection & Outer glass envelope & Sky (atmosphere) \\
\hline$q_{34 \mathrm{rad}}$ & Radiation & Outer absorber pipe & Inner glass envelope \\
\hline$q_{34 \mathrm{cnv}}$ & Convection & Outer absorber pipe & Inner glass envelope \\
\hline$q_{32 \mathrm{cnd}}$ & Conduction & Outer absorber pipe & Inner absorber pipe \\
\hline$q_{21 \mathrm{cnv} v}$ & Convection & Inner absorber pipe & HTF \\
\hline$q_{f}$ & Convection & Absorber pipe inlet & Absorber pipe outlet \\
\hline
\end{tabular}

Figure 12 portrays the linear network model for heat flow between ambient air and HTF. It includes several heat transfer notations and thermal resistances (F. Zaversky et al., 2012).

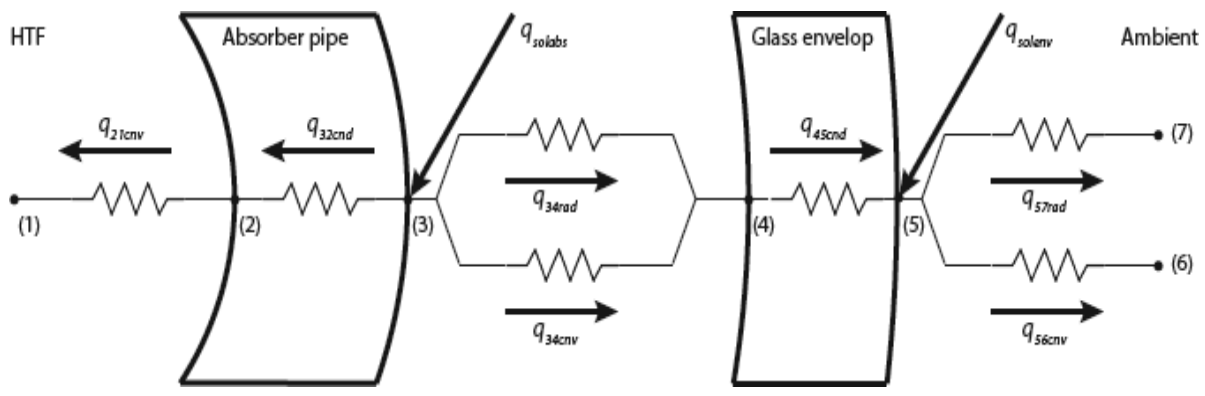

Figure 12. Network of one-dimensional heat transfer. 
The energy balances of thermal resistance model are (S. Kuravi et al., 2013)

$$
\begin{aligned}
& q_{5 \text { solenv }}+q_{45 \mathrm{cnd}}=q_{57 \mathrm{rad}}+q_{56 \mathrm{cnv}} \\
& q_{34 \mathrm{rad}}+q_{34 \mathrm{cnv}}=q_{45 \mathrm{cnd}} \\
& q_{3 \mathrm{solabs}}=q_{32 \mathrm{cnd}}+q_{34 \mathrm{rad}}+q_{34 \mathrm{cnv}} \\
& q_{32 \mathrm{cnd}}=q_{21 \mathrm{cnv}} \\
& q_{21 \mathrm{cnv}}=q_{f}
\end{aligned}
$$

where $q$ is the heat transfer. The unit for ' $q$ ' is $\mathrm{W}$.

$q_{5 \text { solenv }}:$ Solar irradiation absorption of glass envelope at the outer surface.

$q_{45 \text { cnd }}:$ Conduction from inner to outer glass envelope surface.

$q_{57 \mathrm{rad}}$ : Radiations from outer glass envelope surface to the sky.

$q_{56 \text { cnv }}$ : Convection from outer glass envelope surface to ambient.

$q_{34 \text { rad }}:$ Radiation from outer absorber pipe to inner glass envelope surface.

$q_{34 \mathrm{cnv}}$ : Convection from outer absorber pipe to inner glass envelope surface.

$q_{3 \text { solabs }}:$ Absorption of solar irradiation at outer surface absorber pipe.

$q_{32 \text { cnd }}:$ Conduction from outer to the inner absorber pipe surface.

$q_{21 \text { cnv }}$ : Convection from inner surface of absorber pipe to HTF.

$q_{f}:$ Absorbed heat by HTF.

Through convection heat transfer from the inner surface of absorber pipe to HTF is calculated by (M. Ouagued et al., 2012; Z. D. Cheng et al., 2010).

$$
q_{21 c n v}=\pi D_{2} L h_{21 c n v}\left(T_{2}-T_{1}\right)
$$

where $L[\mathrm{~m}]$ is the length of PTC, $h_{21 c n v}$ is the convection heat transfer coefficient of HTF, $D_{2}[\mathrm{~m}]$ is the diameter of the absorber pipe inner surface, $T_{2}$ is the inner surface temperature of absorber pipe, and $T_{1}$ is the bulk temperature of the HTF calculated in Kelvin.

$$
T_{1}=\left(T_{f i}+T_{f o}\right) / 2
$$

where $T_{f i}$ and $T_{f o}$ are the HTF temperatures at inlet and outlet of the absorber pipe and convection heat transfer coefficient, and $h_{21 \mathrm{cnv}}$, for $q_{21 \mathrm{cnv}}$ can be determined using (S. S. Pawar et al., 2013)

$$
h_{21 c n v}=N u k_{f} / D_{2}
$$

where $N u$ is the Nusselt number for HTF base on absorber pipe internal diameter and $k_{f}[\mathrm{~W} / \mathrm{mK}]$ is the thermal conductance of heat transfer fluids at bulk temperature.

Laminar, turbulent and transitional flow case to calculate the Nusselt number $(\mathrm{Nu})$ and the nature of flow is calculated by (M. J. Hosseini et al., 2014)

$$
R e_{f}=\left(\rho_{f} V_{f} D_{2}\right) / \mu_{f}
$$


where $\rho_{f}\left[\mathrm{~kg} / \mathrm{m}^{3}\right]$ is the density at bulk temperature, $V_{f}[\mathrm{~m} / \mathrm{s}]$ is the flow velocity, and $\mu_{f}[\mathrm{~kg} / \mathrm{m} . \mathrm{s}]$ is the dynamic viscosity of heat transfer fluids.

The $\left(R e_{f}<2300\right)$ for laminar flows, $N u=4.36$ and turbulent flows $\left(2300 \leq R e_{f}<5 \times 10^{6}, 0.5 \leq P r \leq 2000\right)$, and correlation between Nusselt number and friction factor is determined by Gnielinski (H. Benoit et al., 2016).

$$
N u=\frac{\frac{f}{8}\left(R e_{f}-1000\right) P r}{1+12.7 \sqrt{\frac{f}{8}}\left(\operatorname{Pr}^{\frac{2}{3}}-1\right)}
$$

where $\operatorname{Pr}=$ Prandtl number determined at the HTF temperature, $T_{1}$, and $f$ is the friction factor for the absorber pipe inner surface.

$$
f=\left(0.79 \log R e_{f}-1.64\right)^{-2}
$$

The amount of heat flowing through conduction directed from outer to the inner surface of the absorber pipe can be determined with (K. Vignarooban et al., 2015)

$$
q_{32 c n d}=\frac{2 \pi L k_{a b s}\left(T_{3}-T_{2}\right)}{\ln \left(\frac{D_{3}}{D_{2}}\right)}
$$

where $k_{a b s}[\mathrm{~W} / \mathrm{mK}]$ is the thermal conductivity of absorber material, $T_{2}$ and $T_{3}$ represent the temperature of the inner and outer surfaces of the absorber pipe, $D_{2}[\mathrm{~m}]$ and $D_{3}[\mathrm{~m}]$ denote the diameter of absorber pipe inner and outer surfaces, and $L[\mathrm{~m}]$ is the length of PTC.

Radiation and convection heat transfer ensue between absorber and glass envelope. Convection heat transfer relies on the pressure of annulus gas, and radiation heat transfer is due to the difference between the temperature of the glass and absorber pipe. The amount of heat flowing through convection and radiation from the outer surface of absorber pipe to inner surface of the glass envelope can be evaluated by Eq. (12) and (13) (F. Zaversky et al., 2012; M. Roesle et al., 2012).

$$
q_{34 c n v}=\pi D_{3} L h_{34 c n v}\left(T_{3}-T_{4}\right)
$$

where $h_{34 c n v}$ represents the convection heat transfer coefficient of annulus gas, and $L[\mathrm{~m}]$ is the length of PTC.

$$
q_{34 \mathrm{rad}}=\frac{\sigma \pi D_{3} L\left(T_{3}{ }^{4}-T_{4}{ }^{4}\right)}{\frac{1}{\varepsilon_{a b s}}+\frac{\left(1-\varepsilon_{e n v}\right) D_{3}}{\varepsilon_{e n v} D_{4}}}
$$

where $L[\mathrm{~m}]$ : Length of PTC, $\sigma$ : Stefan-Boltzmann constant $\left(\mathrm{W} / \mathrm{m}^{2}-\mathrm{K}^{4}\right), \varepsilon_{a b s}$ : Emissivity of absorber pipe outer surface, $\varepsilon_{\text {env }}$ : Emissivity of glass envelope outer surface, $T_{3}[\mathrm{~K}]$ : Temperature of the outer surface of the absorber pipe, $T_{4}[\mathrm{~K}]$ : Inner glass envelope surface temperature, $D_{4}[\mathrm{~m}]$ : Diameter of inner glass envelope surface, and $D_{3}[\mathrm{~m}]$ : Outer surface diameter of absorber pipe.

$$
D_{3}=D_{2}+\Delta D_{23}
$$

$\Delta D_{23}[\mathrm{~m}]$ : Two times the thickness of annular space.

The amount of heat flowing through conduction from the inner to the outer surface of glass envelope is determined by (F. Zaversky et al., 2012)

$$
q_{45 c n d}=2 \pi L k_{e n v}\left(T_{4}-T_{5}\right) / \ln \left(\frac{D_{5}}{D_{4}}\right)
$$

where $L$ : Length of PTC [m], $k_{\text {env }}$ : Thermal conductivity of envelope $[\mathrm{W} / \mathrm{mK}], T_{4}[\mathrm{~K}]$ and $T_{5}[\mathrm{~K}]$ : Glass envelope 
temperature from the inner and outer surface, and $D_{4}[\mathrm{~m}]$ and $D_{5}[\mathrm{~m}]$ : Inner and outer surface diameter of glass envelope.

$$
D_{5}=D_{4}+\Delta D_{45}
$$

$\Delta D_{45}[\mathrm{~m}]:$ Twice the thickness of glass envelope.

Radiation and convection heat transfer occur from the glass envelope to the outer atmosphere. The convection will be either natural or forced, depending on the speed of the wind. Heat loss through radiation occurs due to the temperature difference between the glass envelope and atmosphere, given by (M. Fenot et al., 2011)

$$
q_{57 \mathrm{rad}}=\sigma \pi D_{5} L \varepsilon_{e n v}\left(T_{5}{ }^{4}-T_{7}{ }^{4}\right)
$$

where $\varepsilon_{e n v}$ : Emissivity of glass envelope outer surface, $\sigma$ : Stefan-Boltzmann constant $\left(\mathrm{W} / \mathrm{m}^{2}-\mathrm{K}^{4}\right), D_{5}[\mathrm{~m}]$ : Outer surface diameter of the glass envelope, $L[\mathrm{~m}]$ : PTC length, $T_{5}[\mathrm{~K}]$ : Glass envelope outer surface temperature, and $T_{7}$ [K]: Estimated effective sky temperature (Forristall, 2003).

$$
T_{7}=T_{6}-8
$$

$T_{6}$ is the ambient temperature in $\mathrm{K}$.

The amount of heat flowing over convection from glass envelope outer surface to ambient is computed in (F. Zaversky et al., 2012)

$$
q_{56 c n v}=\pi D_{5} L h_{56 c n v}\left(T_{5}-T_{6}\right)
$$

where $h_{56 c n v}$ : Convection heat transfer coefficient of air, $T_{5}$ : Outer surface temperature of glass envelope in ' $\mathrm{K}$ ', $T_{6}$ : Ambient temperature in ' $\mathrm{K}$ ', and $D_{5}$ : Glass envelope outer surface diameter in ' $\mathrm{m}$ '.

Solar irradiation absorption of glass envelope at the outer surface and absorber pipe is determined with Eq. (18) and (19) (C. K. Ho et al., 2011):

$$
q_{5 \text { solenv }}=q^{\prime \prime} W L \eta_{\text {env }} \alpha_{e n v}
$$

where $q$ " presents the incident solar flux/area for collector aperture $\left[\mathrm{W} / \mathrm{m}^{2}\right], W$ : Width of aperture concentrator $[\mathrm{m}], \eta_{\text {env }}$ : At the glass envelope the effective optical efficiency, and $\alpha_{e n v}$ : Absorptance of the glass envelope (F. Zaversky et al., 2012).

$$
q_{3 s o l a b s}=q^{\prime \prime} W L \eta_{a b s} \alpha_{a b s}
$$

where $\eta_{a b s}$ : Effective optical efficiency at absorber, and $\alpha_{a b s}$ : Absorptance of the absorber. Correspondingly, the effective optical efficiency on the absorber, $\eta_{a b s}$, for $q_{3 \text { solabs }}$ can be calculated by (C. K. Ho et al., 2011)

$$
\eta_{a b s}=\eta_{e n v} \tau_{e n v}
$$

where $\tau_{e n v}$ is the glass envelope transmittance and $\eta_{e n v}$ is the effective optical efficiency at the glass envelope. It is very difficult to calculate losses due to optical inefficiencies. Therefore, all-optical properties are combined to form one optical efficiency equation. The $\eta_{\text {env }}$ for $q_{5 \text { solenv }}$ is determined using the following given equation (C. K. Ho et al., 2011; H. Benoit et al., 2016).

$$
\eta_{e n v}=\varepsilon_{1} \varepsilon_{2} \varepsilon_{3} \varepsilon_{4} \varepsilon_{5} \varepsilon_{6} \rho_{c l} K_{i n c}
$$

where $\varepsilon_{1}$ : Error caused by collector shadowing because of shielding, bellows and supports, $\varepsilon_{2}$ : Tracking error, $\varepsilon_{3}$ : Geometry error owing to reflector misalignment, and $\varepsilon_{4}$ : Error because of dirt on the reflector surface (H. Benoit et al., 2016). 
$\varepsilon_{4}=\eta_{o} / \rho_{c l}$

$\varepsilon_{5}$ : Error caused by dirt on the collector, recommended by Duffie and Beckman (H. Benoit et al., 2016).

$\varepsilon_{5}=\left(1+\varepsilon_{4}\right) / 2$

$\varepsilon_{6}$ : Unaccounted errors, $\rho_{c l}$ : Clean mirror reflectance, $\eta_{o}$ : Reflectivity and $K_{i n c}$ : Incident angle modifier.

Heat absorbed by HTF can be calculated by (M. J. Montes et al., 2009)

$q_{f}=\dot{m} C_{p, f}\left(T_{f o}-T_{f i}\right)$

where $\dot{m}[\mathrm{~kg} / \mathrm{s}]$ : mass flow rate of HTF, and $C_{p, f}[\mathrm{~J} / \mathrm{kg} . \mathrm{K}]$ : specific heat of HTF. The width of the collector aperture can be obtained using Eq. (22) if the outer diameter and concentration ratio of absorber pipe are known (M. Roesle et al., 2012).

$$
C=W / \pi D_{3}
$$

where $C$ is the concentration ratio.

\section{Analytical Model (Without Glass Sleeve)}

Heat transfer in PTC the parabolic trough without the glass envelope is shown in Figure 13. Solar irradiation after falling on concentrator reflected the absorber pipe. Figure 14 shows a different dimensional view of the absorber pipe.

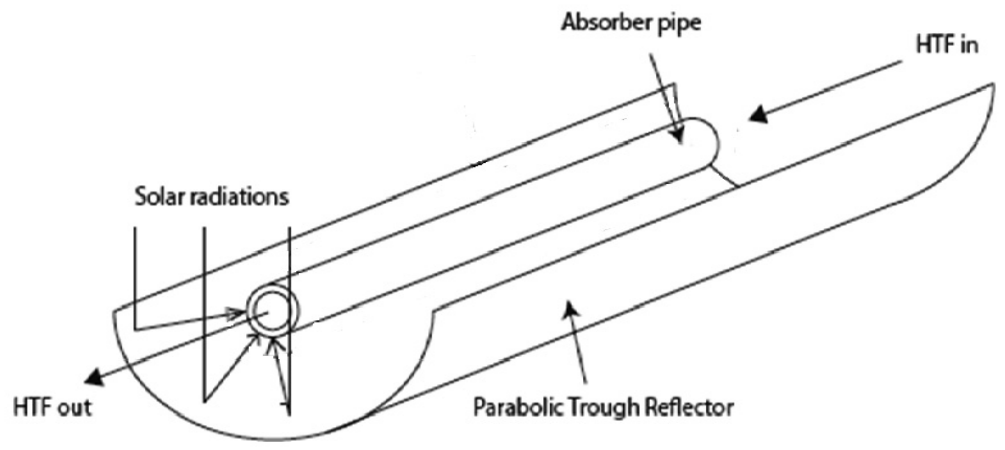

Figure 13. A solar parabolic trough collector without glass envelope.

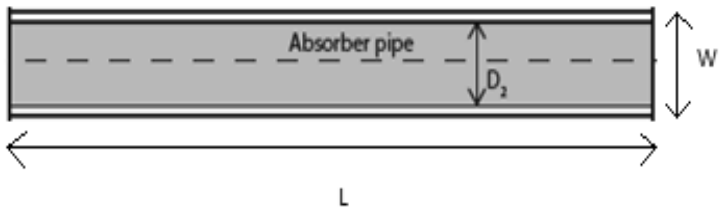

(a)

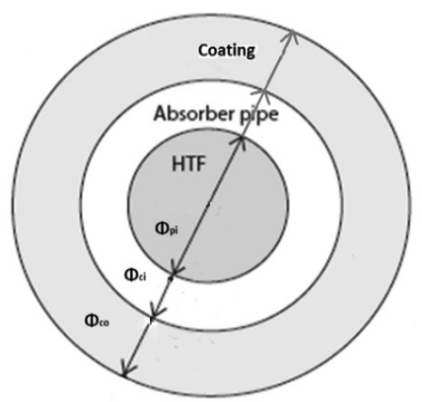

(b)

Figure 14. PTC and absorber pipe with different dimensions. 
Figure 15 illustrates the one-dimensional model of heat transfer along with ambient air and the HTF. It integrates the numerous heat transfer notations and thermal resistances as given in Table 3 (A. A. Hachicha et al., 2013).

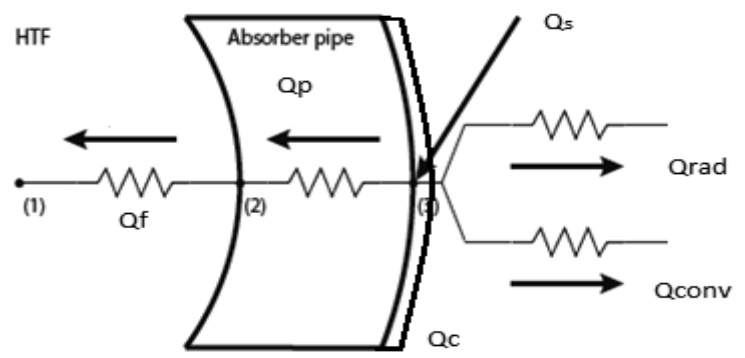

Figure 15. Heat transfer without glass envelope (one-dimensional model).

Table 3. Heat transfer mode with their flow direction.

\begin{tabular}{|c|c|c|c|}
\hline \multirow{2}{*}{$\begin{array}{c}\text { Heat Flux } \\
\text { (Watt/m) }\end{array}$} & Heat Transfer Mode & \multicolumn{2}{|c|}{ Heat Transfer Path } \\
\cline { 3 - 4 } & & From & To \\
\hline$Q_{s}$ & Solar irradiation absorption & Incident solar irradiation & Outer absorber pipe coating \\
\hline$Q_{\text {rad }}$ & Radiation & Outer absorber pipe coating & Sky (atmosphere) \\
\hline$Q_{c o n v}$ & Convection & Outer absorber pipe coating & Sky (atmosphere) \\
\hline$Q_{c}$ & Conduction & Outer absorber pipe coating & Outer absorber pipe \\
\hline$Q_{p}$ & Conduction & Outer absorber pipe & Inner absorber pipe \\
\hline$Q_{f}$ & Conduction & Inner absorber pipe & HTF \\
\hline$Q_{u} L$ & Convection & Absorber pipe inlet & Absorber pipe outlet \\
\hline
\end{tabular}

By the thermal resistance network (Nodal analysis), the energy balances are (S. Kuravi et al., 2013; D. Barlev et al., 2011)

$Q_{s}=Q_{u}+Q_{l}$

$Q_{l}=Q_{\text {conv }}+Q_{\text {rad }}$

Since all heat fluxes are in series, therefore,

$Q_{u}=Q_{c}=Q_{p}=Q_{f}$

where

$Q_{s}[\mathrm{~W} / \mathrm{m}]$ : Solar irradiation absorption at the outer surface of pipe coating.

$Q_{u}[\mathrm{~W} / \mathrm{m}]:$ Useful amount of heat flux for HTF.

$Q_{l}[\mathrm{~W} / \mathrm{m}]$ : Heat loss due to convection and radiation from coating surface to atmosphere.

$Q_{\text {conv }}[\mathrm{W} / \mathrm{m}]:$ Heat loss as a result of convection.

$Q_{\text {rad }}[\mathrm{W} / \mathrm{m}]$ : Heat loss because of radiation. 
$Q_{c}[\mathrm{~W} / \mathrm{m}]$ : Heat transfer through conduction from coating outer surface to absorber pipe outer surface.

$Q_{p}[\mathrm{~W} / \mathrm{m}]:$ Heat transfer via conduction from outer to the inner surface of absorber pipe.

$Q_{f}[\mathrm{~W} / \mathrm{m}]:$ Heat transfer via convection from inner pipe to heat transfer fluids (HTF).

The amount of radiation absorber pipe receive after optical losses can be calculated by (F. Zaversky et al., 2012)

$Q_{s}=\frac{G C A_{c o} \eta \alpha}{L}$

where $G\left[\mathrm{~W} / \mathrm{m}^{2}\right]$ is the solar irradiance or Direct Normal Irradiations (DNI), $C$ is the concentration ratio, $A_{c o}\left[\mathrm{~m}^{2}\right]$ is the surface area of black coating, $\eta$ is the reflectivity of concentrator sheet, $\alpha$ is the absorptivity of black coating, and $L[\mathrm{~m}]$ denotes the length of the absorber pipe.

Radiation heat transfer through absorber coating to the surrounding atmosphere can be calculated as (L. Godson et al., 2010)

$Q_{\text {rad }}=\varepsilon \sigma \pi \phi_{c o}\left(T_{c o}{ }^{4}-T_{a}^{4}\right)$

where : Emissivity of absorber pipe coating, which is $\varepsilon=0.0005333 T_{c o}-0.0856$

$\sigma:$ Stefan-Boltzmann constant $\left(\mathrm{W} / \mathrm{m}^{2}-\mathrm{K}^{4}\right)$.

$\phi_{c o}[\mathrm{~m}]:$ Outer diameter of coating.

$T_{c o}[\mathrm{~K}]$ : Outer surface coating temperature.

$T_{a}[\mathrm{~K}]$ : Ambient temperature.

Convection heat transfer through absorber coating to the surrounding atmosphere can be calculated as (C. K. Ho et al., 2011)

$Q_{\text {conv }}=N_{u \text { air }} K_{\text {air }} \pi\left(T_{c o}-T_{a}\right)$

where $K_{\text {air }}[\mathrm{W} / \mathrm{mK}]$ : Thermal conductivity of air, $T_{c o}[\mathrm{~K}]$ : Outer surface coating temperature, and $T_{a}[\mathrm{~K}]$ : Ambient temperature.

The Nusselt number for the calculation of $Q_{c o n v}$ can be calculated as (R. V. Padilla et al., 2011; S. S. Pawar et al., 2013)

$N_{\text {uair }}=0.4+0.54 \operatorname{Re}_{\text {air }}{ }^{0.53}$

where $R e_{\text {air }}$ is the Reynolds number, and it depends upon the speed of air.

$R e_{a i r}=\frac{\rho_{\text {air }} V_{\text {air }} \phi_{c o}}{\mu_{\text {air }}}$

where $\rho_{\text {air }}\left[\mathrm{Kg} / \mathrm{m}^{3}\right]$ represents the density of air, $V_{\text {air }}[\mathrm{m} / \mathrm{s}]$ : Velocity of air, and $\mu_{\text {air }}[\mathrm{Kg} / \mathrm{ms}]$ : Viscosity of air

Conduction heat transfer through coating can be obtained by Eq. (26) (F. Agyenim et al., 2010)

$Q_{c}=\frac{2 K_{c} \pi\left(T_{c o}-T_{c i}\right)}{\ln \frac{\phi_{c o}}{\phi_{c i}}}$

where $K_{c}[\mathrm{~W} / \mathrm{mK}]$ : Thermal conductivity of coating, $T_{c i}[\mathrm{~K}]$ : Temperature of inner surface of coating, and $\phi_{c o}[\mathrm{~m}]$ and $\phi_{c i}[\mathrm{~m}]$ : Outer and Inner diameter of coating or outer diameter of pipe. 
Conduction heat transfer through the pipe can be calculated by (M. J. Hosseini et al., 2014)

$$
Q_{p}=\frac{2 K_{p} \pi\left(T_{c i}-T_{p i}\right)}{\ln \frac{\phi_{c i}}{\phi_{p i}}}
$$

where $K_{p}[\mathrm{~W} / \mathrm{mK}]$ : Thermal conductivity of pipe, $T_{p i}[\mathrm{~K}]$ : Inner pipe surface temperature, $\phi_{c i}[\mathrm{~m}]$ : Inner diameter of coating or Outer diameter of pipe, and $\phi_{p i}[\mathrm{~m}]$ : Inner diameter of pipe.

Heat transfer from the absorber pipe to HTF through convection can be evaluated as (M. Ouagued et al., 2012)

$$
Q_{f}=N_{u} K_{f} \pi\left(T_{p i}-T_{\text {fiterative }}\right)
$$

where $K_{f}[\mathrm{~W} / \mathrm{mK}]$ : Thermal conductivity of HTF.

$T_{p i}[\mathrm{~K}]$ : Temperature of the inner pipe surface.

$T_{f \text { iterative }}[\mathrm{K}]$ : Mean or average bulk temperature of HTF.

$T_{f \text { iterative }}$ is used for iterative purposes. For the first iteration, it is a mathematical average of inlet and outlet temperature.

For the laminar flow, the value of the Nusselt number can be directly taken as $N_{u}=4.36$. For the turbulent flow, the Nusselt number can be obtained by using correlation (S. S. Pawar et al., 2013):

$$
N_{u}=\frac{\frac{f}{8}\left(R e_{f}-1000\right) P r}{1+12.7 \sqrt{\frac{f}{8}}\left(\operatorname{Pr}^{\frac{2}{3}}-1\right)}
$$

where $r$ : Prandtl number evaluated at the HTF temperature, $T_{f}$ iterative, and $f$ : Friction factor of the absorber pipe for the inner surface that can be determined as

$$
f=\left(0.79 \log R e_{f}-1.64\right)^{-2}
$$

The Reynolds number for HTF can be calculated as (S. S. Pawar et al., 2013)

$$
R e_{f}=\frac{\rho_{f} V_{f}}{\mu_{f}}
$$

where $\rho_{f}\left[\mathrm{Kg} / \mathrm{m}^{3}\right]$ : Density of HTF, $V_{f}[\mathrm{~m} / \mathrm{s}]$ : Velocity of HTF, and $\mu_{f}[\mathrm{Kg} / \mathrm{ms}]$ : Viscosity of HTF. All these properties of HTF are evaluated at $T_{f}$ iterative.

Axial heat gain of HTF through the whole length of pipe can be calculated from Eq. (29) (M. I. Roldan et al., 2013).

$$
Q_{u} L=m C_{p}\left(T_{f o}-T_{f i}\right)
$$

where $m[\mathrm{Kg} / \mathrm{s}]$ : Mass flow rate of HTF, $C_{p}[\mathrm{~J} / \mathrm{Kg}-\mathrm{K}]$ : Specific heat capacity of $\mathrm{HTF}, T_{f o}[\mathrm{~K}]$ : Outlet temperature of HTF, and $T_{f i}[\mathrm{~K}]$ : Inlet temperature of HTF.

The collector aperture width can be estimated by Eq. (30) if the outer diameter of the absorber pipe and concentration ratio are known (M. Ouagued et al., 2012).

$$
C=\frac{W}{\pi \phi_{c o}}
$$




\section{Heat Transfer Model to Calculate Outlet Temperature of the Trough}

The equations from the heat balance, performed on the absorber pipe of the parabolic trough, are used to build a mathematical model of the PTC system to calculate the outlet temperature of the heat transfer fluid. A very complex model is established, which can predict the HTF outlet temperature after several iterations. To minimize the time taken to solve such prolonged model, a computer program is developed using the software Engineering Equation Solver (EES) as shown in Figure 16. It does not only minimize the time taken to solve the model, but also automate the process of iterations. Thus, precise results can be obtained. The basic function of EES is to provide numerical solutions to linear or nonlinear algebraic and differential equations. It also provides physical and chemical properties of widely used fluids, that is, water, steam, thermal oils, organic compounds, inert gases, and also few solids.

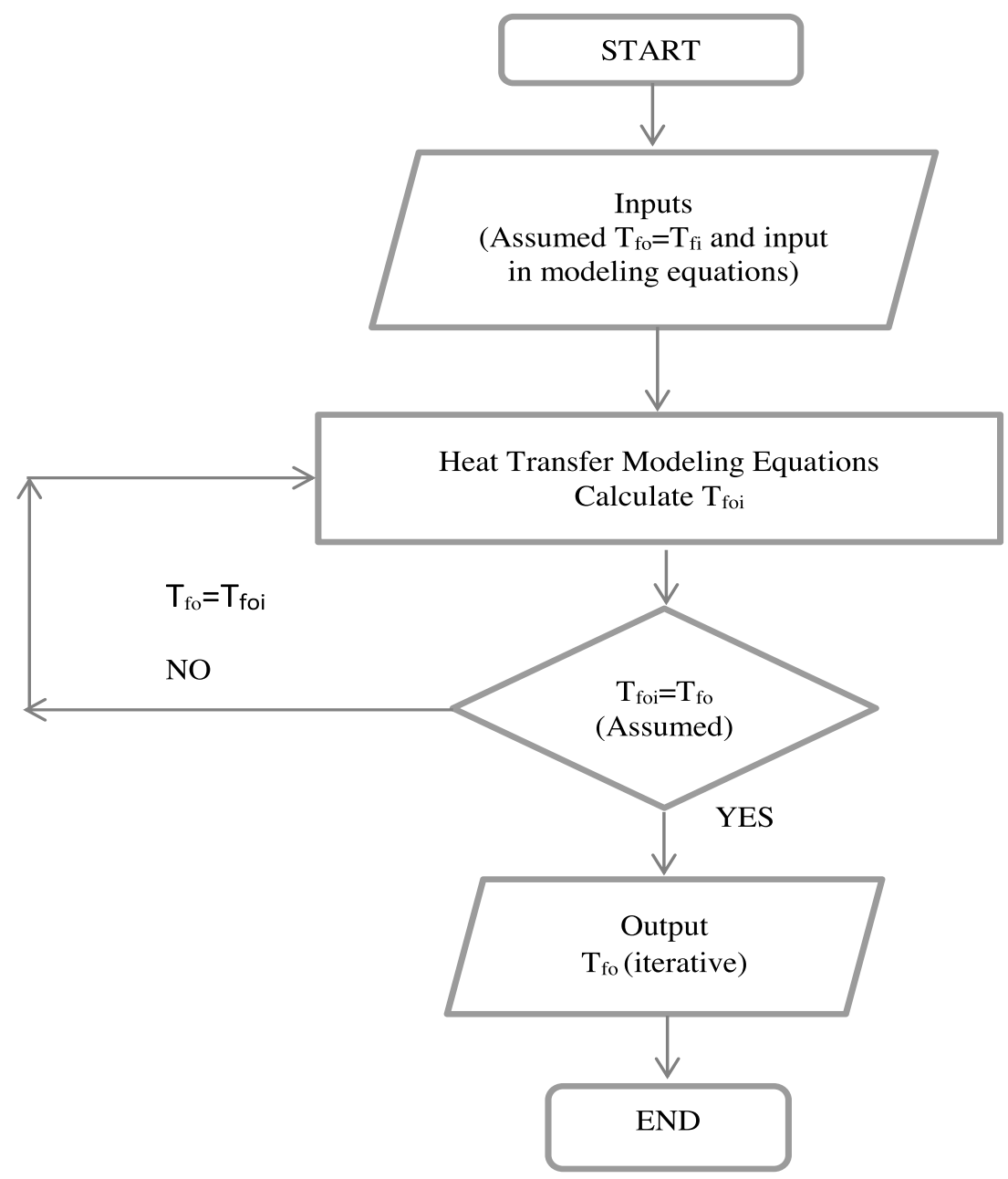

Figure 16. Algorithm EES programming.

A parametric table allows the program to run on multiple inputs and provide multiple outputs, and many additional features make EES a powerful tool for developing mathematical models of various types of engineering systems. The following is the algorithm used to solve equations to obtain $T_{f o}$ (outlet temperature). 


\section{EES Code for PTC System (With Glass Sleeve)}

The mathematical model is developed for the calculation of outlet temperature of the HTF, which is transformed into an EES program.

FUNCTION getNuf (Ref, Pr)

$\operatorname{if}(\operatorname{Ref}<2300)$ then

$$
\text { getNuf : }=4.36
$$

else

$$
\begin{aligned}
& \mathrm{f}:=\left(0.79^{*} \log 10(\operatorname{Ref})-1.64\right)^{\wedge}(-2) \\
& \text { getNuf }:=\left(\left((\mathrm{f} / 8)^{*}(\operatorname{Ref}-1000) * \operatorname{Pr}\right) /\left(1+12.7^{*} \operatorname{sqrt}(\mathrm{f} / 8)^{*}\left(\operatorname{Pr}^{\wedge}(2 / 3)-1\right)\right)\right)
\end{aligned}
$$

endif

"if(Ref $>5$ e5) then Call Warning('Ref out of range.’)"

END

Subprogram SOLVER (Tfi,qdd,L,C,mdot,dia2,deldia23,deldia34,deldia45,E1,E2,E3,E6,rhocl,no,theta,Eabs,Ee nv,kabs,kenv,aabs,aenv,tenv,h56,h34,Tamb,Tfo_itr :R_Tfo,T3,T5,eff,Ref)

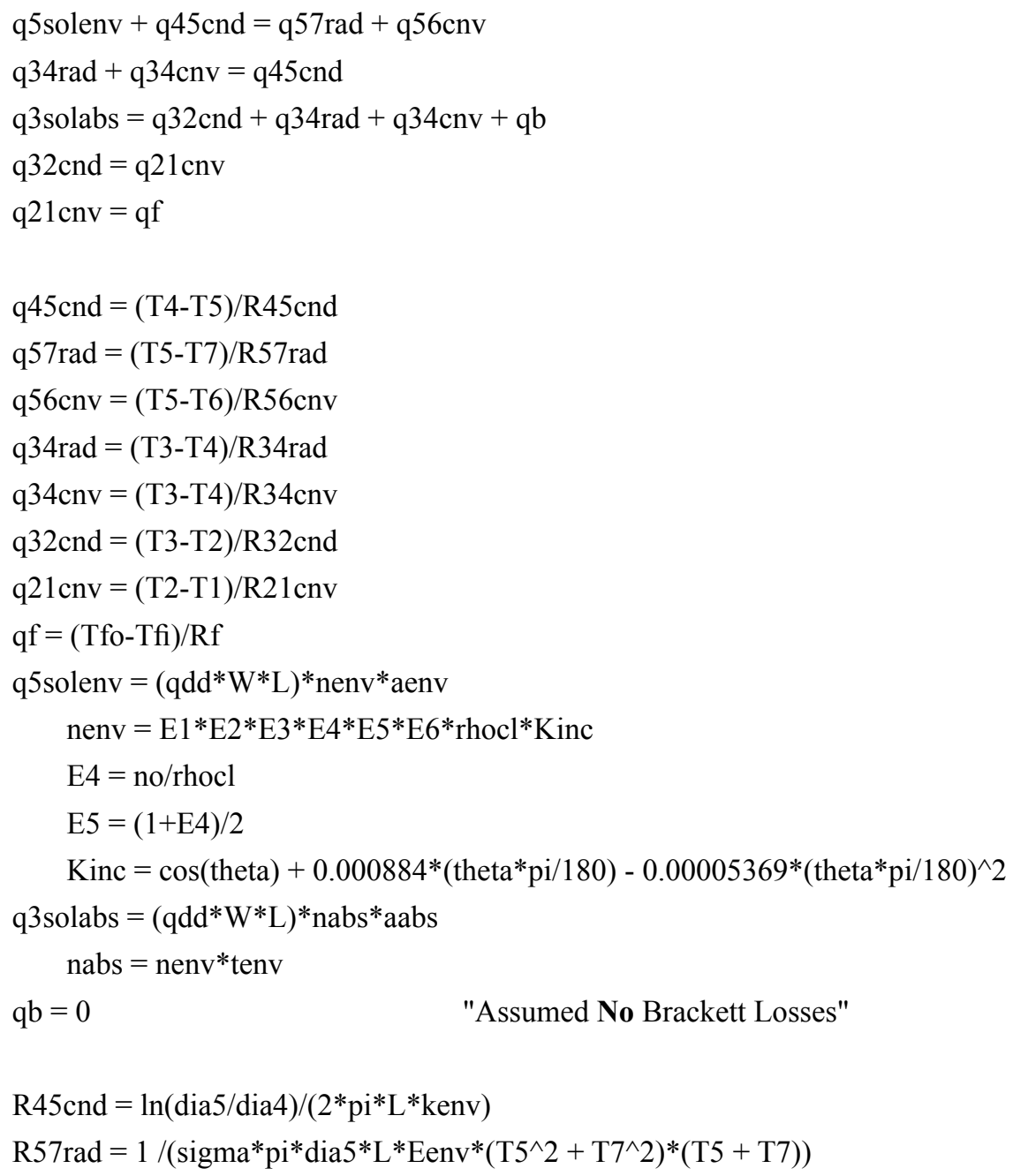




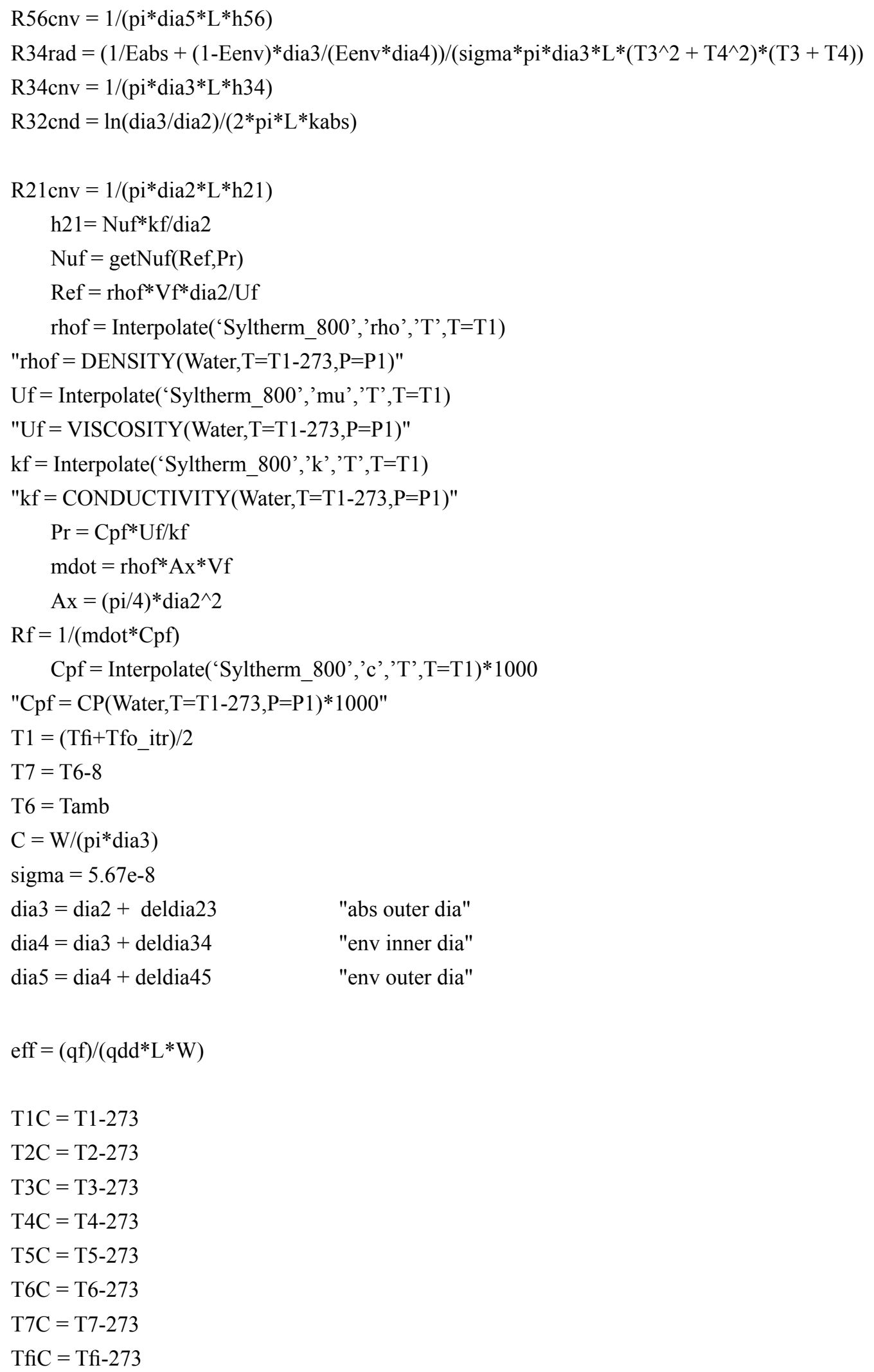


$\mathrm{TfoC}=\mathrm{Tfo}-273$

$\mathrm{dT}=\mathrm{Tfo}-\mathrm{Tfi}$

R_Tfo $=$ Tfo

END

\section{PROCEDURE ITERATE}

(Tfi,qdd,L,C,mdot,dia2,deldia23,deldia34,deldia45,E1,E2,E3,E6,rhocl,no,theta,Eabs,Eenv,kabs,kenv,aabs,ae nv,tenv,h56,h34,Tamb:R_Tfo,dT,T3,T5,eff,Ref,D,n)

$\mathrm{n}:=0$

Tfo:=Tfi

R_Tfo $:=$ Tfo

Repeat

$\mathrm{n}:=\mathrm{n}+1$

Tfo := R_Tfo

Call SOLVER

(Tfi,qdd,L,C,mdot,dia2,deldia23,deldia34,deldia45,E1,E2,E3,E6,rhocl,no,theta,Eabs,Eenv,kabs,kenv,aabs,ae nv,tenv,h56,h34,Tamb,Tfo :R_Tfo,T3,T5,eff,Ref)

$$
\begin{aligned}
& \mathrm{D}=\text { abs(Tfo-R_Tfo) } \\
& \mathrm{dT}=\mathrm{R} \_ \text {Tfo }-\mathrm{Tfi}
\end{aligned}
$$

Until (( $\mathrm{D}<=0.001)$ OR $(\mathrm{n}=100))$

if $((\mathrm{n}=100)$ OR $(\mathrm{D}>0.001))$ then Call Warning $(<$ Not converged. $>)$

END

\$ifnot parametrictable

$$
\begin{aligned}
& \text { Tfi }=25+273 \\
& \text { qdd }=800 \\
& \mathrm{~L}=7.8 \\
& \mathrm{C}=22.42 \\
& \text { mdot }=0.09307 \\
& \text { dia2 }=66 / 1000 \\
& \text { deldia23 }=4 / 1000 \\
& \text { deldia34 }=39 / 1000 \\
& \text { deldia45 }=6 / 1000 \\
& \mathrm{E} 1=0.974 \\
& \mathrm{E} 2=0.994 \\
& \mathrm{E} 3=0.98 \\
& \mathrm{E} 6=0.96 \\
& \text { rhocl }=0.935
\end{aligned}
$$$$
\text { "inlet temperature of HTF }[\mathrm{K}] \text { " }
$$$$
\text { "solar radiations [W/m2]" }
$$$$
\text { "length of PTC [m]" }
$$$$
\text { "concentration ratio of PTC" }
$$$$
\text { "mass flow rate of HTF }[\mathrm{kg} / \mathrm{s}](\text { density }=930 \mathrm{~kg} / \mathrm{m} 3) "
$$

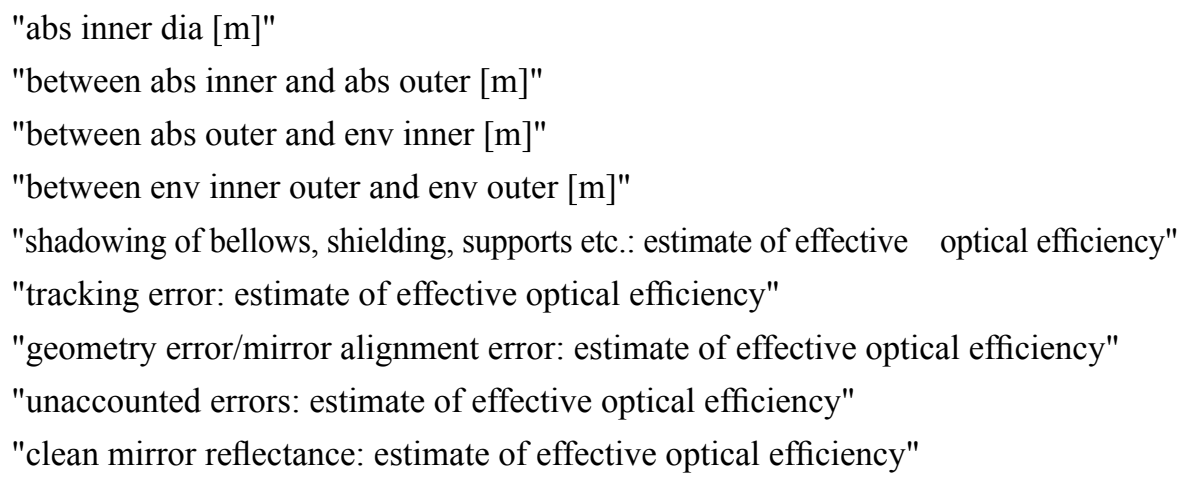




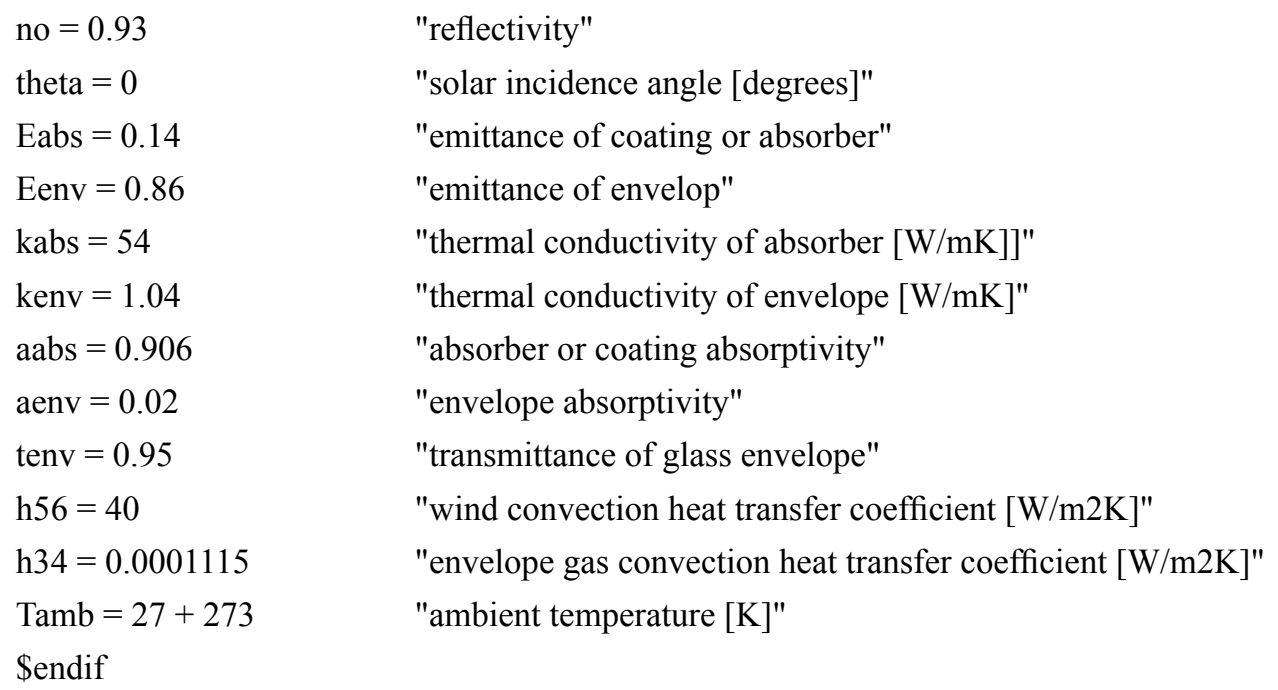

\section{CALL ITERATE}

(Tfi,qdd,L,C,mdot,dia2,deldia23,deldia34,deldia45,E1,E2,E3,E6,rhocl,no,theta,Eabs,Eenv,kabs,kenv,aabs,ae nv,tenv,h56,h34,Tamb:Tfo,dT,T3,T5,eff,Ref,D,n)

\section{EES Code for PTC System (Without Glass Sleeve)}

The mathematical model is generated for a PTC system without glass sleeve in EES. The code is given as follows:

\$Bookmark Inputs

\begin{tabular}{|c|c|}
\hline $\mathrm{C}=100$ & $\{$ Concentration Ratio $\}$ \\
\hline $\mathrm{G}=500$ & $\left\{\mathrm{DNI}\left(\right.\right.$ Watts $\left.\left./ \mathrm{m}^{\wedge} 2\right)\right\}$ \\
\hline $\mathrm{P}_{-} \mathrm{O}=101.3$ & $\{$ Pressure $(\mathrm{kpa})\}$ \\
\hline T_amb $=298$ & $\{$ Ambient Temperature $(\mathrm{k})\}$ \\
\hline phi_pi $=0.010$ & $\{$ Pipe Inside Dia $(\mathrm{m})\}$ \\
\hline phi_co $=0.013$ & $\{$ Coating outside Dia $(\mathrm{m})\}$ \\
\hline phi_ci $=0.012$ & $\{$ Coating inside Dia (meters) $\}$ \\
\hline eta $=0.95$ & $\{$ Optical Efficiency\} \\
\hline alpha $=0.8$ & $\{$ Absorbance $\}$ \\
\hline sigma $=5.67 \mathrm{e}-8$ & $\{$ Stefan-Boltzman Constant $\}$ \\
\hline V_air=1 & $\{$ Velocity of Air $(\mathrm{m} / \mathrm{s})\}$ \\
\hline K_co $=300$ & $\{$ Th. Conductivity of coating $(\mathrm{W} / \mathrm{mk})\}$ \\
\hline K_c $=400$ & $\{$ Th. Conductivity of copper pipe (W/mk) $\}$ \\
\hline $\mathrm{L}=1$ & $\{$ Length of Trough $(\mathrm{m})\}$ \\
\hline
\end{tabular}


\$Bookmark Temperature Iteration

$\mathrm{T}$ fi $=298$

T_fo $=325.7$

\{Outlet temperature KELVIN (Change Value for Iteration)\}

$\mathrm{Tfm}=(\mathrm{T}$ fi $+\mathrm{T}$ fo $) / 2$

Tfm_i $=\left(T \_f o \_i+T \_f i\right) / 2$

\$Bookmark Model Equations

Q_u $=$ Q_s-Q_L

Q_u=Q_c

\{Heat coating\}

$\mathrm{Q} \_\mathrm{c}=\left(2 * \mathrm{pi} * \mathrm{~K} \_c{ }^{*} \mathrm{~L} *\left(\mathrm{~T} \_\right.\right.$co-T_ci $\left.)\right) /(\ln (\mathrm{phi}$ co $/ \mathrm{phi}$ _ci $))$

Q_u=Q_p

\{Heat pipe\}

$\mathrm{Q} \_p=(2 *$ pi*K_c*L*(T_ci-T_pi $\left.)\right) /(\ln ($ phi_ci/phi_pi $))$

$\mathrm{Q}_{-} \mathrm{u}=\mathrm{Q} \_\mathrm{f}$

\{Heat Fluid\}

Q_f $=$ h_water*pi*phi_pi*L*(T_pi-Tfm)

h_water $=(4.36 *$ CONDUCTIVITY $($ Water,T $=$ Tfm,P=P_o $)) /$ phi_pi

Q_u $=$ mw_dot* $\mathrm{CP}\left(\right.$ Water, $\left.\mathrm{T}=\mathrm{Tfm}, \mathrm{P}=\mathrm{P} \_\mathrm{o}\right) * 1000 *\left(\mathrm{~T} \_\right.$fo_i-T_fi $)$

$\{$ Heat Axial Fluid $\}$

$\mathrm{Re} \_\mathrm{w}=\left(\mathrm{DENSITY}\left(\right.\right.$ Water,T$\left.=\mathrm{Tfm}, \mathrm{P}=\mathrm{P} \_\mathrm{o}\right) * \mathrm{phi} \_\mathrm{pi} * \mathrm{~V} \_$water $) / \mathrm{VISCOSITY}\left(\right.$ Water,T$\left.=\mathrm{Tfm}, \mathrm{P}=\mathrm{P} \_\mathrm{o}\right)$

Re_w $=2100$

mw_dot $=\left(D E N S I T Y\left(W a t e r, T=T f m, P=P \_o\right)\right) *\left(p i *\left(p h i \_p i^{\wedge} 2\right) / 4\right) * V \_$water

Q_s $=\mathrm{G}^{*} \mathrm{C}^{*}$ pi*phi_co*L*eta*alpha

$\{$ Heat Solar\}

Q_L=Q_rad+Q_conv

$\{$ Heat Losses\}

Q_rad=sigma*epsilon*pi*L*phi_co* $\left(T \_c{ }^{\wedge} 4-T\right.$ _amb $\left.{ }^{\wedge} 4\right)$

\{Radiation\}

epsilon $=0.0005333 *$ T_co- 0.0856

Q_conv=h_air*pi*phi_co*L*(T_co-T_amb)

\{Air Convection\}

h_air $=\left(\right.$ CONDUCTIVITY $\left.\left(A i r, T=T \_a m b\right) / p h i \_c o\right) *\left(N u \_a i r\right)$

$\mathrm{Nu}$ _air $=0.4+0.54 * \mathrm{Re} \_{ }^{\mathrm{air}}{ }^{\wedge} 0.53$

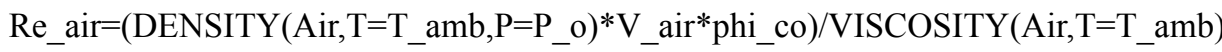

T_fo_celsius $=T$ _fo_i -273.15 


\section{RESULTS AND DISCUSSION}

Using the above equations, validate the analytical model to calculate the outlet temperature of HTF for a specific PTC. Input parameter and dimensions for the specific PTC are $\mathrm{C}=24.11 ; \mathrm{L}=7.8 \mathrm{~m} ; \mathrm{D}_{2}=66 \mathrm{~mm} ; \Delta \mathrm{D}_{23}=4 \mathrm{~mm} ; \Delta \mathrm{D}_{34}$ $=43 \mathrm{~mm} ; \Delta \mathrm{D}_{45}=6 \mathrm{~mm} ; \epsilon_{1}=0.974 ; \epsilon_{2}=0.994 ; \epsilon_{3}=0.98 ; \epsilon_{6}=0.96 ; \rho_{\mathrm{cl}}=0.935 ; \eta_{\mathrm{o}}=0.93 ; \theta=0^{0} ; \epsilon_{\mathrm{abs}}=0.1378 ; \epsilon_{\mathrm{env}}$ $=0.85 ; \mathrm{k}_{\mathrm{abs}}=54 \mathrm{~W} / \mathrm{mK} ; \mathrm{k}_{\mathrm{env}}=1.04 \mathrm{~W} / \mathrm{K} ; \alpha_{\mathrm{abs}}=0.905 ; \alpha_{\mathrm{env}}=0.02 ; \tau_{\mathrm{env}}=0.95 ; \mathrm{h}_{56 \mathrm{cnv}}=40 \mathrm{~W} / \mathrm{m}^{2} \mathrm{~K} ; \mathrm{h}_{34 \mathrm{cnv}}=0.0001115$ $\mathrm{W} / \mathrm{m}^{2} \mathrm{~K}$. These values were selected on the basis of experiments as defined by Dudley. Three different cases for heat transfer characteristics and mass flow rates were used to estimate the values of HTF outlet temperatures and compared with those given by Dudley as given in Table 4 (M. Ouagued et al., 2012; F. Zaversky et al., 2012; C. K. Ho et al., 2011). The output of the existing mathematical model was found in accordance with the experimental results. Hence, the model is verified.

Table 4. Experimental results and proposed model comparison from the literature.

\begin{tabular}{|c|c|c|c|c|c|c|}
\hline Case & $\begin{array}{c}\mathbf{q} \\
\left(\mathbf{W} / \mathbf{m}^{\mathbf{2}}\right)\end{array}$ & $\begin{array}{c}\dot{\mathbf{m}} \\
(\mathbf{k g} / \mathbf{s})\end{array}$ & $\begin{array}{c}\mathbf{T}_{\mathbf{a}} \\
(\mathbf{K})\end{array}$ & $\begin{array}{c}\mathbf{T}_{\mathbf{f i}} \\
(\mathbf{K})\end{array}$ & $\begin{array}{c}\mathbf{T}_{\mathbf{f o}} \\
(\mathbf{K})\end{array}$ & $\begin{array}{c}\mathbf{T}_{\text {fo (model) }} \\
(\mathbf{K})\end{array}$ \\
\hline 1 & 933.7 & 0.6782 & 294.2 & 375.2 & 397 & 396.2 \\
\hline 2 & 937.9 & 0.6206 & 301.8 & 570.8 & 589.9 & 591.3 \\
\hline 3 & 920.9 & 0.5457 & 302.5 & 652.5 & 671 & 673.5 \\
\hline
\end{tabular}

\section{Statistical Analysis}

Due to the nature of the study, the verified model needs to be run for various thermal fluids to obtain their respective outlet temperature for comparison. Further statistical analysis of the results may give us a generalized correlation for HTF outlet temperature. In the field of solar energy engineering, deterministic modelling is commonly used for predicting the response of a model against known input parameters. Probabilistic modelling provides a more realistic approach as a distribution of output is obtained over a range of probable values for input parameters. For this purpose, at first, probabilistic modelling is performed for Syltherm 800, a commonly used thermal fluid. Regression methods could then be employed to build output correlations that are valid for a probable range of input variables. This approach is taken for establishing correlations of HTF temperature attained at the end of a linear PTC, which will be most useful at the experimentation stage. The correlation can be used to predict the outlet temperature of the HTF being used at the experimentation stage, hence further verifying the established theoretical model (R. V. Padilla et al., 2011; M. J. Montes et al., 2009).

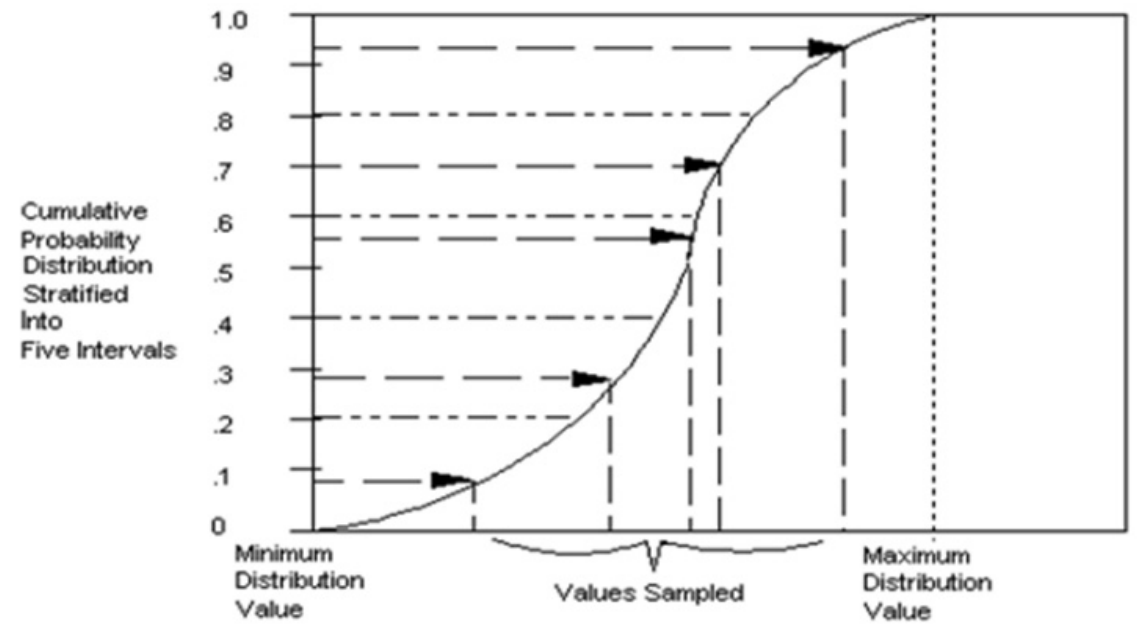

Figure 17. Five iterations of Latin Hypercube Sampling. 
For probabilistic modelling, a sufficient number of the samples is required within the prescribed ranges. For this purpose, the Latin Hypercube Sampling technique is used. For LHS sampling, it is important first to decide how many are to be taken. 5000 samples were found to be sufficient for this study. The technique to obtain the samples can easily be understood from Figure 17 (F. Zaversky et al., 2012).

\section{Probabilistic Modeling}

To continue with probabilistic modelling, appropriate scopes of input variables are recognized, being dependent on framework limitations, normal judgment, or literature.

Table 5. Expected arrays of all factors and comparing qualities of samples got via Latin hypercube sampling technique.

\begin{tabular}{|c|c|c|c|c|c|c|c|c|}
\hline \multirow{2}{*}{ Factors } & \multirow{2}{*}{ Unit } & \multicolumn{3}{|c|}{ Expected arrays of factors } & \multicolumn{3}{|c|}{ Latin hypercube samples } & \multirow{2}{*}{$\begin{array}{c}\% \\
\text { Difference in } \\
\text { Mean } \\
\end{array}$} \\
\hline & & Minimum & Maximum & Mean & Minimum & Maximum & Mean & \\
\hline $\mathrm{T}_{\mathrm{fi}}$ & $\mathrm{K}$ & 288 & 623 & 456 & 288 & 623 & 455.21 & $0.17 \%$ \\
\hline q", & $\mathrm{W} / \mathrm{m}^{2}$ & 50 & 1420 & 735 & 50.19 & 1420 & 734.34 & $0.09 \%$ \\
\hline $\mathrm{L}$ & $\mathrm{m}$ & 0.2 & 8 & 4.1 & 0.2014 & 8 & 4.0942 & $0.14 \%$ \\
\hline $\mathrm{C}$ & - & 10 & 100 & 55 & 10.01 & 100 & 54.919 & $0.15 \%$ \\
\hline$\dot{\mathrm{m}}$ & $\mathrm{kg} / \mathrm{s}$ & 0.005 & 1 & 0.502 & 0.00517 & 0.9999 & 0.5043 & $-0.47 \%$ \\
\hline $\mathrm{D}_{2}$ & $\mathrm{~m}$ & 0.008 & 0.01 & 0.009 & 0.008 & 0.01 & 0.009 & $0 \%$ \\
\hline$\Delta \mathrm{D}_{23}$ & $\mathrm{~m}$ & 0.002 & 0.008 & 0.005 & 0.002001 & 0.007999 & 0.0050 & $-0.04 \%$ \\
\hline$\Delta \mathrm{D}_{34}$ & $\mathrm{~m}$ & 0.02 & 0.05 & 0.035 & 0.02001 & 0.05 & 0.0349 & $0.02 \%$ \\
\hline$\Delta \mathrm{D}_{45}$ & $\mathrm{~m}$ & 0.002 & 0.008 & 0.005 & 0.002 & 0.008 & 0.0050 & $-0.04 \%$ \\
\hline$\epsilon_{1}$ & - & 0.85 & 1 & 0.925 & 0.85 & 1 & 0.9250 & $0.00 \%$ \\
\hline$\epsilon_{2}$ & - & 0.85 & 1 & 0.925 & 0.85 & 1 & 0.9250 & $0.00 \%$ \\
\hline$\epsilon_{3}$ & - & 0.85 & 1 & 0.925 & 0.85 & 1 & 0.9249 & $0.01 \%$ \\
\hline$\epsilon_{6}$ & - & 0.85 & 1 & 0.925 & 0.85 & 1 & 0.925 & $0 \%$ \\
\hline$\rho_{\mathrm{cl}}$ & - & 0.85 & 1 & 0.925 & 0.85 & 1 & 0.9249 & $0.00 \%$ \\
\hline$\eta_{\mathrm{o}}$ & - & 0.85 & 1 & 0.925 & 0.85 & 1 & 0.9249 & $0.01 \%$ \\
\hline $\mathrm{K}_{\mathrm{inc}}$ & - & 0.1 & 1 & 0.55 & 0.1001 & 0.9999 & 0.5500 & $-0.0082 \%$ \\
\hline$\epsilon_{\mathrm{abs}}$ & - & 0 & 0.5 & 0.25 & 0.00003 & 0.5 & 0.2498 & $0.05 \%$ \\
\hline$\epsilon_{\text {env }}$ & - & 0.5 & 1 & 0.75 & 0.5001 & 0.9999 & 0.7499 & $0.01 \%$ \\
\hline $\mathrm{k}_{\mathrm{abs}}$ & $\mathrm{W} / \mathrm{mK}$ & 10 & 400 & 205 & 10.02 & 399.9 & 204.93 & $0.03 \%$ \\
\hline $\mathrm{k}_{\mathrm{env}}$ & $\mathrm{W} / \mathrm{mK}$ & 0.75 & 2 & 1.375 & 0.7501 & 2 & 1.3744 & $0.04 \%$ \\
\hline$\alpha_{\mathrm{abs}}$ & - & 0.75 & 1 & 0.875 & 0.75 & 1 & 0.8750 & $0.00 \%$ \\
\hline$\alpha_{\mathrm{env}}$ & - & 0 & 0.01 & 0.005 & 0 & 0.009999 & 0.0049 & $0.04 \%$ \\
\hline$\tau_{\mathrm{env}}$ & - & 0.75 & 1 & 0.875 & 0.75 & 1 & 0.8749 & $0.01 \%$ \\
\hline $\mathrm{h}_{56}$ & $\mathrm{~W} / \mathrm{m}^{2} \mathrm{~K}$ & 20 & 50 & 35 & 20 & 50 & 34.998 & $0.01 \%$ \\
\hline $\mathrm{h}_{34}$ & $\mathrm{~W} / \mathrm{m}^{2} \mathrm{~K}$ & 0.00001 & 0.01 & 0.005 & 0.00001 & 0.01 & 0.0050 & $-0.04 \%$ \\
\hline $\mathrm{T}_{6}$ & $\mathrm{~K}$ & 288 & 333 & 310.5 & 288 & 333 & 310.49 & $0.00 \%$ \\
\hline
\end{tabular}


Table 5 recorded the twenty-six examined variables, the least and most extreme values, and their means. The sort of values is chosen for moderately estimated PTC utilized in household applications. The greatest, for instance, sunpowered radiation has been chosen equal to the extraterrestrial radiation. The $8 \mathrm{~m}$ length $(L)$ has been determined at the most ideal situation of greatest direct typical light (DNI), lowest mass stream rate, greatest fixation proportion, most extreme inlet temperature, relative properties, and least error values. An additional increment in length might expand the liquid temperature past $400^{\circ} \mathrm{C}$, that is, the farthest point of Syltherm 800 for thermal stability (A. A. Lakew et al., 2010; J. Philip et al., 2012). As far as possible, inlet temperature $\left(T_{f}\right)$ has likewise been chosen so as not to surpass $400^{\circ} \mathrm{C}$ at the outlet.

Uniform dispersions are used for the chose variables with the goal that the final correlation is similarly legitimate for the majority of the datasets. LHS procedure was utilized to choose a stratified and randomized example of 5000 values for each variable. Table 5 records the determined methods for the majority of the acquired samples that are practically equivalent to the mean, as shown by the negligible error percentage. This affirms that the chosen sample is a true illustration of the real values (J. Philip et al., 2012).

This illustrative sample is currently utilized in the analytical model established before in EES yield 5000 HTF outlet temperatures. Figure 18 shows that the suitability of the quantity of samples was evaluated utilizing the combined average of the HTF outlet temperatures. The changes in the figure for cumulative mean these temperatures are under $\pm 5 \%$, afterwards 3000 samples. In this manner, these samples should be viewed as adequate for forthcoming investigations of HTF outlet temperatures (A. A. Lakew et al., 2010).

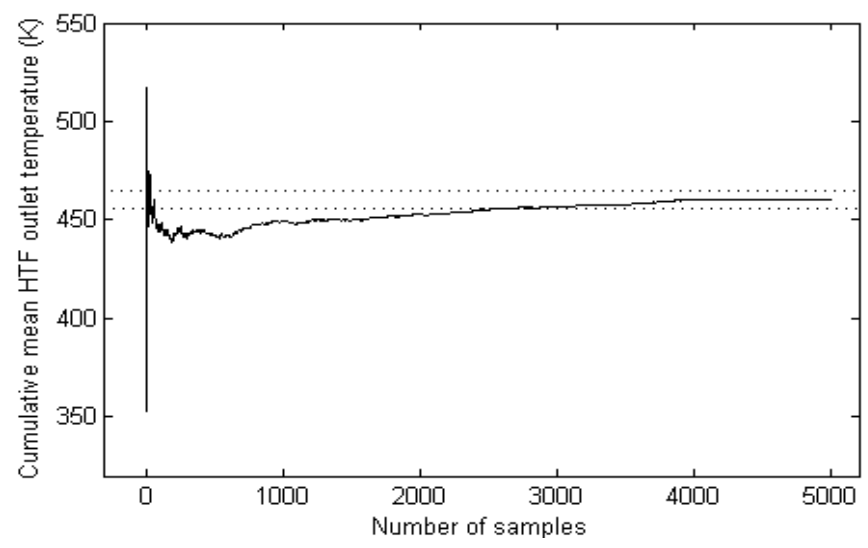

Figure 18. Cumulative mean of HTF outlet temperature vs the number of samples.

Regression analysis was done on the outcomes to define a novel relationship between the chosen 26 constraints and the HTF outlet temperatures. Table 6 gives the acquired coefficients for all variables and their particular P-values. Determining the R-squared statistic, the model built clarifies $98.4 \%$ of the inconstancy in HTF outlet temperature. Besides, just parameters having P-values under 0.05 are accepted as considerably unique in relation to zero at the 95.0\% certainty level. Disregarding the irrelevant parameters, reconsidered coefficients and P-values were resolved as recorded in Table 6 . The relationship was decreased to 9 terms. The incentive for R-squared did not change, and the diminished model additionally clarifies $98.4 \%$ variability.

Therefore, by means of the significant parameters, the reduced correlation is given as

$$
\begin{aligned}
T_{f o}= & -13.9+0.994 T_{f i}+0.00642 q^{\prime \prime}+1.15 L+0.0817 C-16.1 \dot{m}+ \\
& 322 \Delta D_{23}+10.0 \eta_{o}+7.91 K_{\text {inc }}
\end{aligned}
$$

This diminished correlation is legitimate for any PTC utilizing Syltherm 800, which is intended to work inside the input parameters ranges given in Table 5 . The correlation was verified by comparing the results with already published results. 
Table 6. Coefficients for the factors in correlations.

\begin{tabular}{|c|c|c|c|c|c|}
\hline \multirow{2}{*}{ Factors } & \multirow{2}{*}{ Unit } & \multicolumn{2}{|c|}{ Twenty six factor correlation } & \multicolumn{2}{|c|}{ Reduced factors Correlation } \\
\hline & & Coefficient & P-Value & Coefficient & P-Value \\
\hline (Constant) & - & -43.19 & 0.000 & -13.913 & \multirow{6}{*}{0.000} \\
\hline $\mathrm{T}_{\mathrm{fi}}$ & $\mathrm{K}$ & +0.994 & 0.000 & +0.994486 & \\
\hline q" & $\mathrm{W} / \mathrm{m}^{2}$ & +0.00648 & 0.000 & +0.0064190 & \\
\hline $\mathrm{L}$ & $\mathrm{m}$ & +1.162 & 0.000 & +1.1537 & \\
\hline $\mathrm{C}$ & - & +0.0812 & 0.000 & +0.081714 & \\
\hline$\dot{\mathrm{m}}$ & $\mathrm{kg} / \mathrm{s}$ & -16.0 & 0.000 & -16.0610 & \\
\hline $\mathrm{D}_{2}$ & \multirow{4}{*}{$\mathrm{m}$} & +292 & 0.333 & insignificant & - \\
\hline$\Delta \mathrm{D}_{23}$ & & +319 & 0.002 & +321.8 & 0.001 \\
\hline$\Delta \mathrm{D}_{34}$ & & +21.6 & 0.282 & \multirow{7}{*}{ insignificant } & \multirow{7}{*}{-} \\
\hline$\Delta \mathrm{D}_{45}$ & & +4.8 & 0.962 & & \\
\hline$\epsilon_{1}$ & \multirow{9}{*}{-} & +3.07 & 0.445 & & \\
\hline$\epsilon_{2}$ & & +6.226 & 0.122 & & \\
\hline$\epsilon_{3}$ & & +5.936 & 0.140 & & \\
\hline$\epsilon_{6}$ & & +6.74 & 0.094 & & \\
\hline$\rho_{\mathrm{cl}}$ & & +4.091 & 0.31 & & \\
\hline$\eta_{\mathrm{o}}$ & & +9.565 & 0.017 & +10.022 & 0.013 \\
\hline $\mathrm{K}_{\mathrm{inc}}$ & & +7.93 & 0.000 & +7.9093 & 0.000 \\
\hline$\epsilon_{\mathrm{abs}}$ & & -0.064 & 0.958 & \multirow{10}{*}{ insignificant } & \multirow{10}{*}{-} \\
\hline$\epsilon_{\text {env }}$ & & -0.18 & 0.881 & & \\
\hline $\mathrm{k}_{\mathrm{abs}}$ & \multirow{2}{*}{$\mathrm{W} / \mathrm{mK}$} & -0.000064 & 0.967 & & \\
\hline $\mathrm{k}_{\mathrm{env}}$ & & +0.4977 & 0.303 & & \\
\hline$\alpha_{\mathrm{abs}}$ & \multirow{3}{*}{-} & +4.547 & 0.06 & & \\
\hline$\alpha_{\mathrm{env}}$ & & +108.23 & 0.073 & & \\
\hline$\tau_{\text {env }}$ & & +5.88 & 0.115 & & \\
\hline $\mathrm{h}_{56 \mathrm{cnv}}$ & \multirow{2}{*}{$\mathrm{W} / \mathrm{m}^{2} \mathrm{~K}$} & -0.00583 & 0.772 & & \\
\hline $\mathrm{h}_{34 \mathrm{cnv}}$ & & -49.11 & 0.418 & & \\
\hline $\mathrm{T}_{6}$ & $\mathrm{~K}$ & -0.02421 & 0.071 & & \\
\hline
\end{tabular}

The investigation has been directed to such an extent that it distinctively may be used in a secluded manner regarding length. For frameworks with a length exceeding $8.0 \mathrm{~m}$, correlation might be multiple times as in cascaded modules, and for $80 \mathrm{~m}$ length, the correlation was utilized multiple times sequentially, and every time, the leaving temperature of one module will be the input temperature of the following module. Table 6 represents coefficients for the factors in correlations. Additionally, for values between 0.2 to 8 meters, a similar procedure can be connected in light of the fact that the correlation is substantial for $0.2 \mathrm{~m}$ to $8.0 \mathrm{~m}$. Notwithstanding, it was confirmed that the last leave temperature does not surpass $400^{\circ} \mathrm{C}$, which is the thermal constancy limit of Syltherm 800 (A. A. Lakew et al., 2010). The HTF outlet temperature obtained by the correlation was compared with the published results for verification. The comparison is shown in Table 7 (F. Zaversky et al., 2012; Z. D. Cheng et al., 2010). 
Table 7. Correlation verification.

\begin{tabular}{|l|c|c|}
\hline \multicolumn{1}{|c|}{ Literature } & Cheng & Sandia \\
\hline Paper $\mathrm{T}_{\mathrm{fo}}(\mathrm{K})$ & 398.15 & 589.15 \\
\hline Correlation $\mathrm{T}_{\mathrm{fo}}(\mathrm{K})$ & 400.15 & 593.15 \\
\hline
\end{tabular}

For input values chosen, the parameters resolved to be irrelevant incorporate the diameter of the absorber pipe $\left(D_{2}\right)$, the glass envelope thickness $\left(\Delta D_{45}\right)$, and the dispersing among the glass envelope and absorber pipe $\left(\Delta D_{34}\right)$. Consequently, the absorber pipe measurement might be picked, dependent on the mass flowrate prerequisites. As emissivity and conductivity of the absorber pipe $\left(k_{a b s}, \epsilon_{a b s}\right)$ are inconsequential, monetarily suitable choices to copper might be picked to augment absorptivity, on condition that different properties exist in the chosen range. Additionally, properties of the glass envelope $\left(k_{e n v}, \epsilon_{e n v}, \alpha_{e n v}, \tau_{e n v}\right)$ and a few parameters required to ascertain optical proficiency $\left(\rho c_{l}, \epsilon_{l}, \epsilon_{2}, \epsilon_{3}, \epsilon_{6}\right)$ are likewise immaterial. The unimportance of the convection heat transfer coefficient $\left(h_{34 c n v}\right)$ of the low pressure dispersing among pipe and glass envelope is normal. The outside convection heat transfer coefficient $\left(h_{56 \mathrm{cnv}}\right)$ and temperature $\left(T_{6}\right)$ are immaterial, demonstrating that the encompassing temperatures and wind speed do not influence the thermal enactment of PTC (R. V. Padilla et al., 2011; M. J. Montes et al., 2009). Various thermal fluids with wide heat transfer applications are studied for this study after carefully analyzing the properties of the fluids; twenty-three thermal oils are selected for simulation purpose. The property tables of the thermal oils are already integrated into the software used for simulation, Engineering Equation Solver (EES). Some of the properties critical to the study are shown in Table 8 .

Table 8. List of thermal oils and properties.

\begin{tabular}{|c|c|c|c|c|c|c|}
\hline $\begin{array}{c}\text { Thermal } \\
\text { Fluids }\end{array}$ & Composition & $\begin{array}{c}\text { Max. } \\
\text { Temp. } \\
{ }^{\circ} \mathbf{C}\end{array}$ & $\begin{array}{c}\text { Min. } \\
\text { Temp. } \\
{ }^{\circ} \mathbf{C}\end{array}$ & $\begin{array}{c}\text { Flash } \\
\text { point } \\
{ }^{\circ} \mathbf{C}\end{array}$ & $\begin{array}{c}\text { Auto- } \\
\text { ignition } \\
{ }^{\circ} \mathbf{C}\end{array}$ & $\begin{array}{c}\text { Boiling } \\
\text { point } \\
{ }^{\circ} \mathbf{C}\end{array}$ \\
\hline Therminol Vp1 & Biphenyl/diphenyl oxide & 400 & 12 & 124 & 601 & 257 \\
\hline Dowtherm A & Biphenyl/diphenyl oxide eutectic mixture & 400 & 15 & 113 & 599 & 257.1 \\
\hline Syltherm 800 & Dimethyl polysiloxane & 400 & -40 & 177 & 385 & 250 \\
\hline Xceltherm LV & 1,1-Diphenylethane and diphenyl oxide & 371 & -30 & 122 & 604 & 258 \\
\hline Dowtherm G & Di-aryl ethers and diaryl alkyls & 360 & -6 & 137 & 432 & 289 \\
\hline Dowtherm RP & Diaryl alkyl & 350 & -2 & 194 & 385 & 353 \\
\hline Xceltherm HT & Dewaxed paraffins and alkylated aromatics & 350 & 2 & 168 & 450 & 333 \\
\hline Therminol 66 & Modified terphenyl & 345 & -3 & 184 & 374 & 359 \\
\hline Paratherm_HR & Alkylated bi-phenyl & 343 & 20 & 149 & - & 337 \\
\hline Dowtherm MX1 & Alkylated aromatics & 330 & -10 & 165 & 420 & 328 \\
\hline Dowtherm Q & Diphenylethane and alkylated aromatics & 330 & -35 & 120 & 412 & 267 \\
\hline Paratherm_NF & Hydrotreated mineral oil & 325 & 30 & 149 & 413 & 371 \\
\hline Xceltherm 600 & Hydrogenated white oil & 316 & -5 & 178 & 349 & 367 \\
\hline Therminol XP & White mineral oil & 315 & -20 & 199 & 346 & 358 \\
\hline Therminol 59 & Alkyl substituted aromatic & 315 & -49 & 177 & 372 & 289 \\
\hline Dowtherm J & Isomers of an alkylated aromatic & 315 & -80 & 57 & 420 & 181 \\
\hline Marlotherm SH & Aromatic dibenzyl toluene & 300 & -5 & 180 & 330 & 330 \\
\hline Paratherm_HE & Mineral oil & 300 & 40 & 210 & 332 & 343 \\
\hline Paratherm GLT & Alkylated aromatic & 288 & 30 & 171 & 300 & 371 \\
\hline
\end{tabular}




\section{Comparison of Thermal Oil Properties}

Properties of different thermal fluids have been plotted against temperature to study behavioural alteration of fluids. The graphical comparison with increasing fluid temperature depicts the variable drop of density, approximately constant thermal conductivity with little change of viscosity, and specific heat capacity. Figure 19 shows density and viscosity on the primary vertical axis, specific heat capacity, and thermal conductivity on the secondary vertical axis against temperature. The units of properties are given in Table 9 (M. I. Roldan et al., 2013; J. Philip et al., 2012).

Table 9. Thermal properties unit.

\begin{tabular}{|c|c|}
\hline Thermal properties & Units \\
\hline Temperature & Kelvin $(\mathrm{K})$ \\
\hline Density & $\mathrm{Kg} / \mathrm{m}^{3}$ \\
\hline Dynamic Viscosity & Poise \\
\hline Specific Heat Capacity & $\mathrm{KJ} / \mathrm{Kg}-\mathrm{K}$ \\
\hline Thermal Conductivity & $\mathrm{W} / \mathrm{m}-\mathrm{K}$ \\
\hline
\end{tabular}

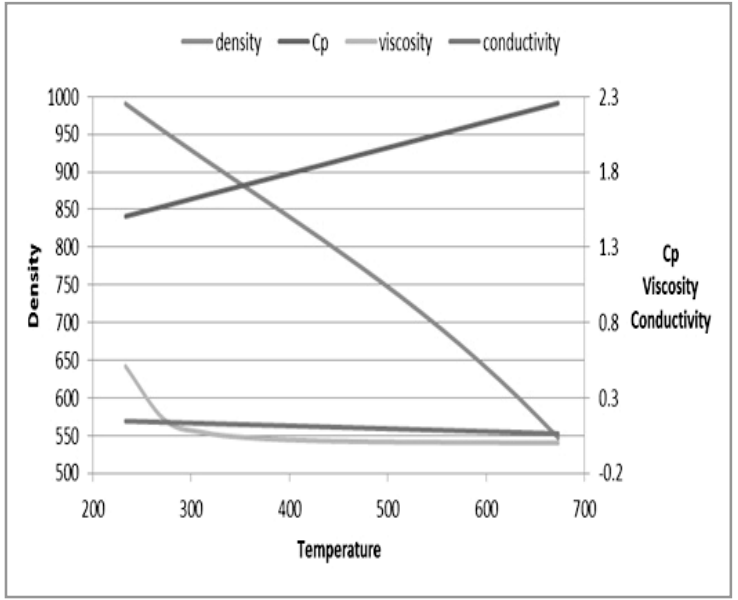

Syltherm 800

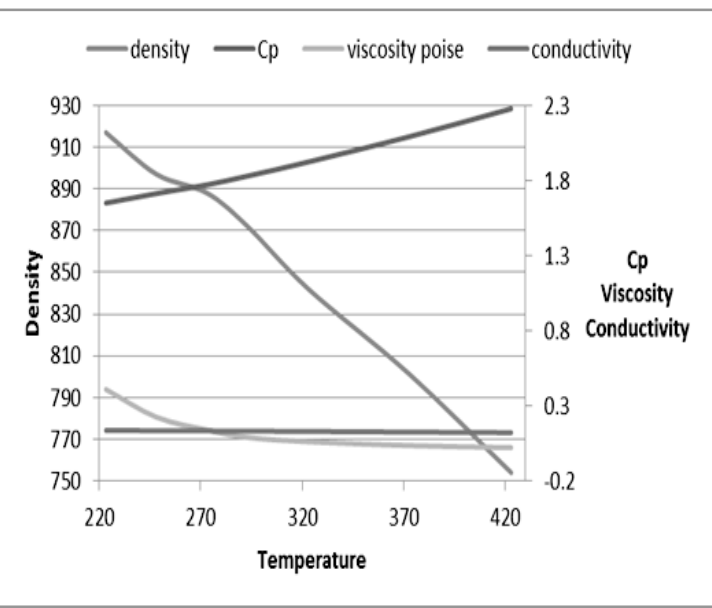

Dowtherm J

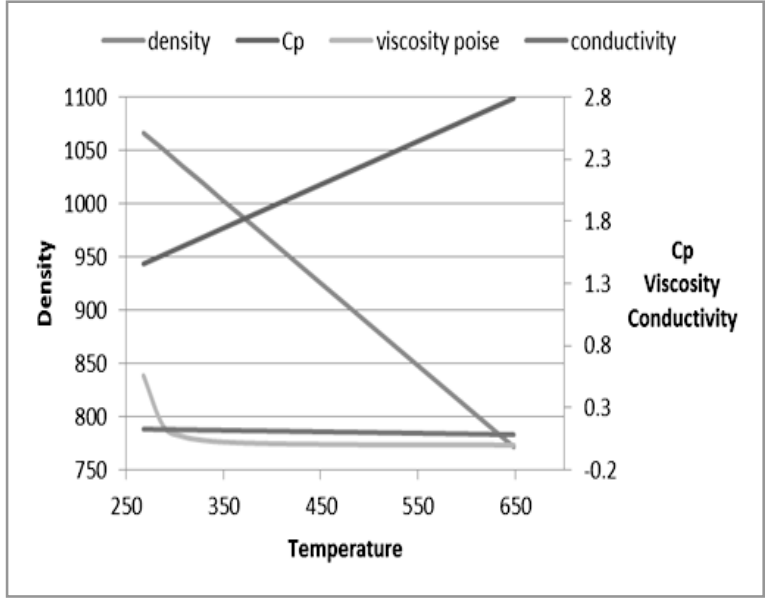

Dowtherm G

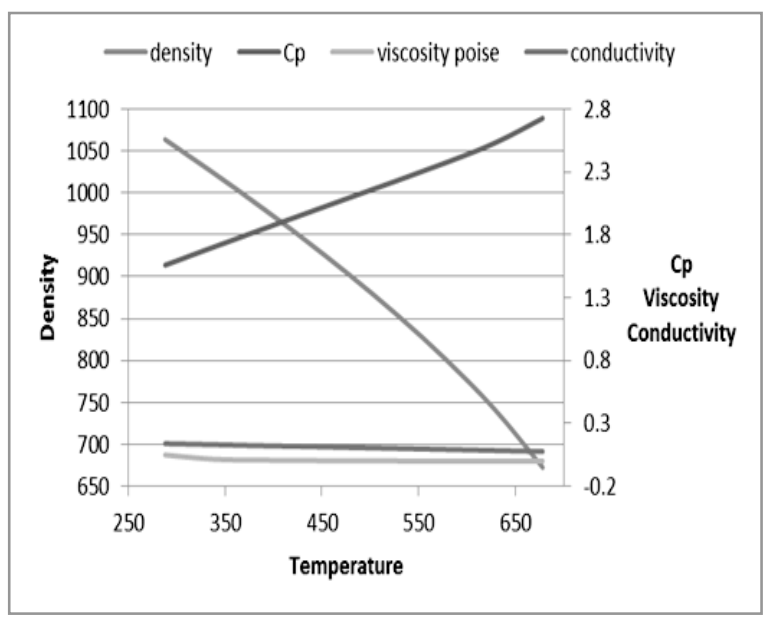

Dowtherm A 


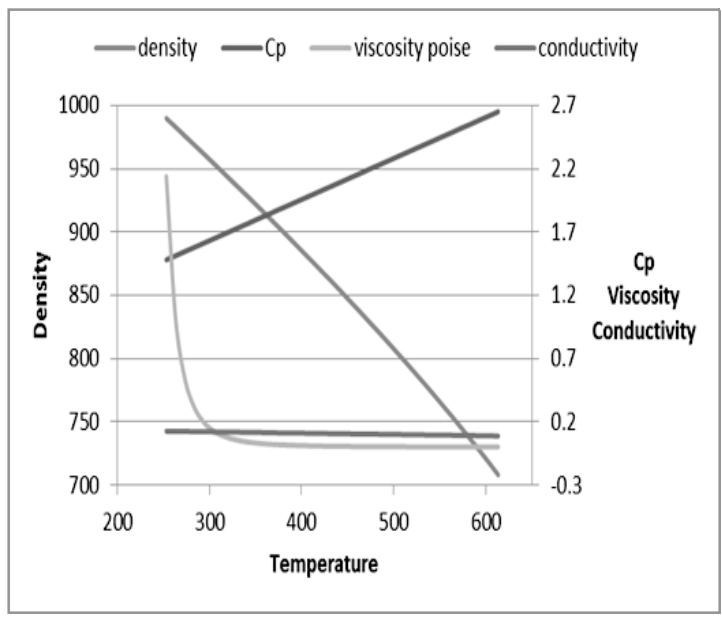

Dowtherm MX

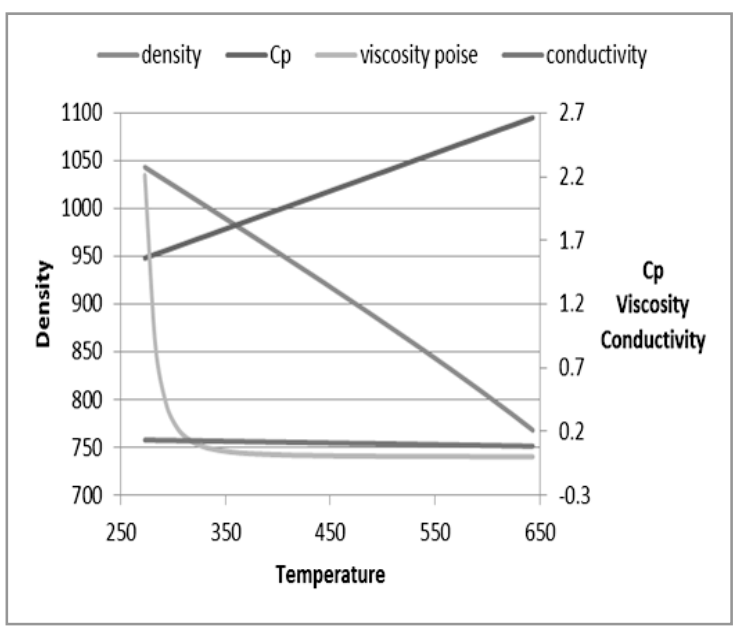

Dowtherm RP

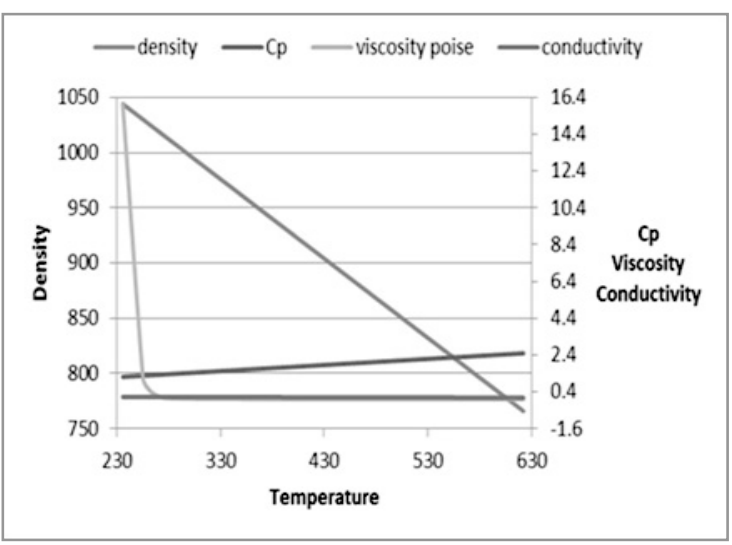

Xceltherm HT

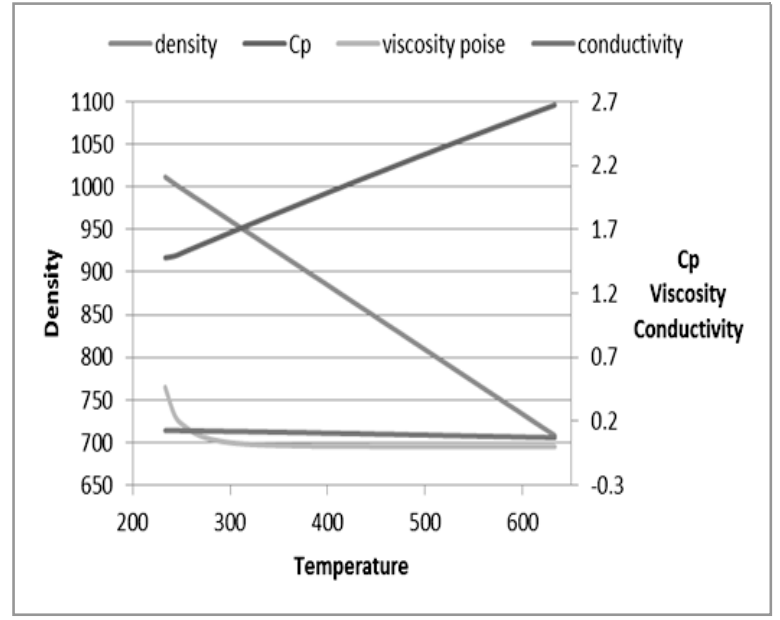

Dowtherm Q

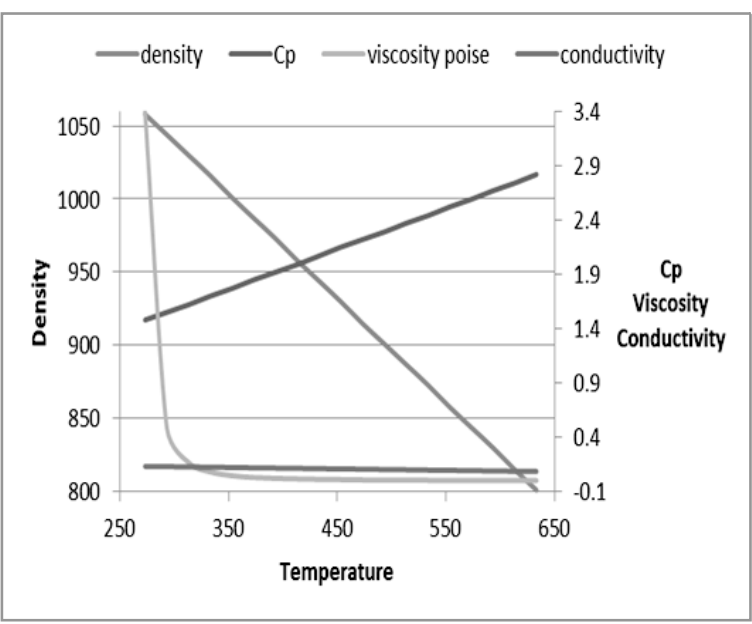

Marlotherm

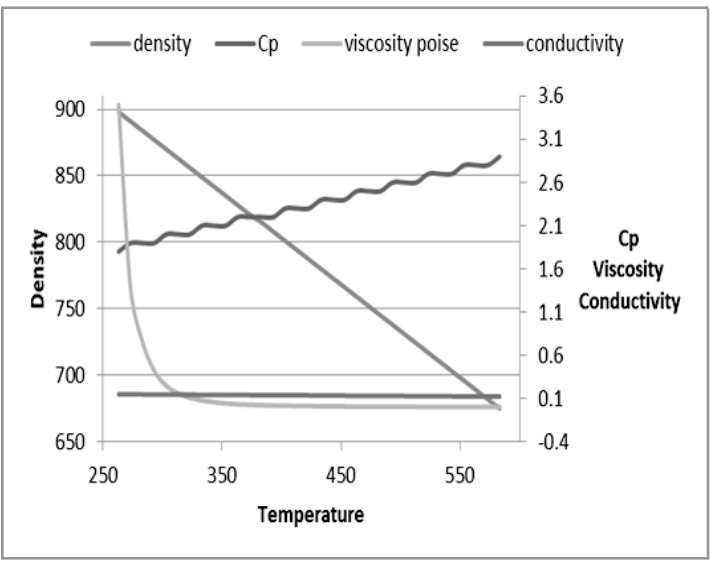

Paratherm GLT 


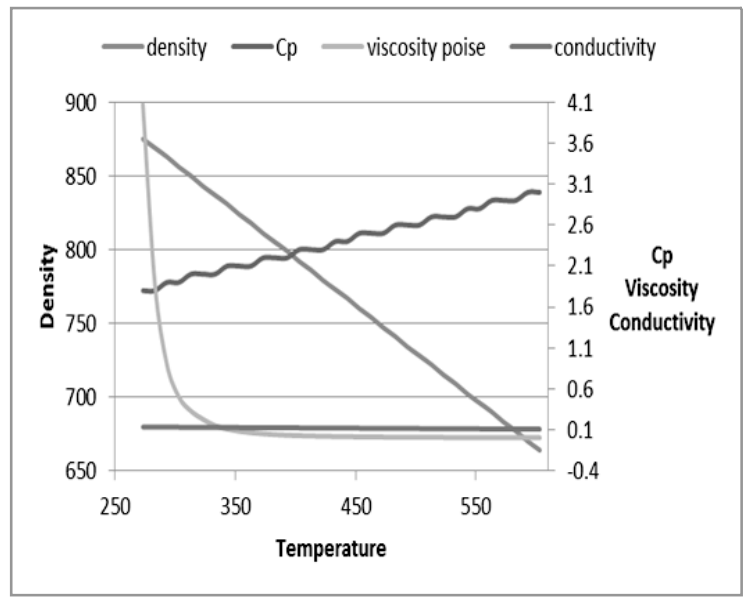

Paratherm HE

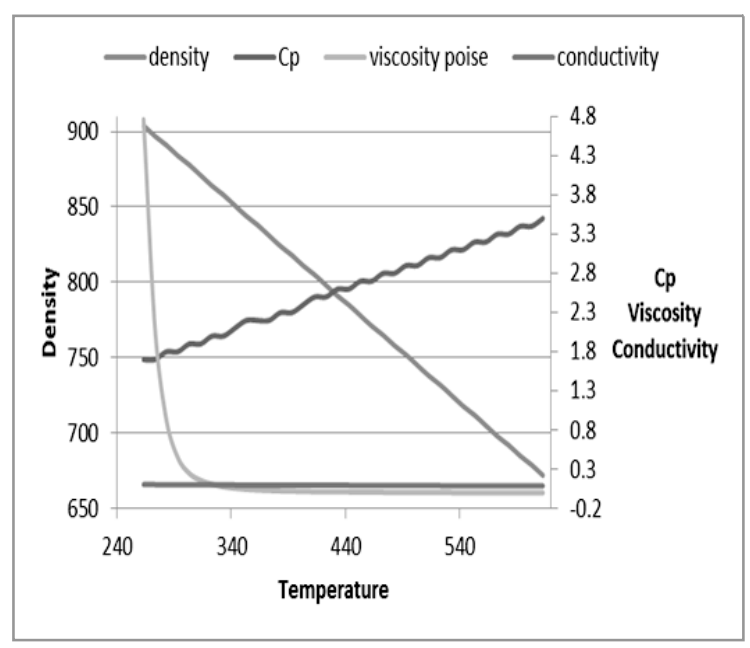

Paratherm NF

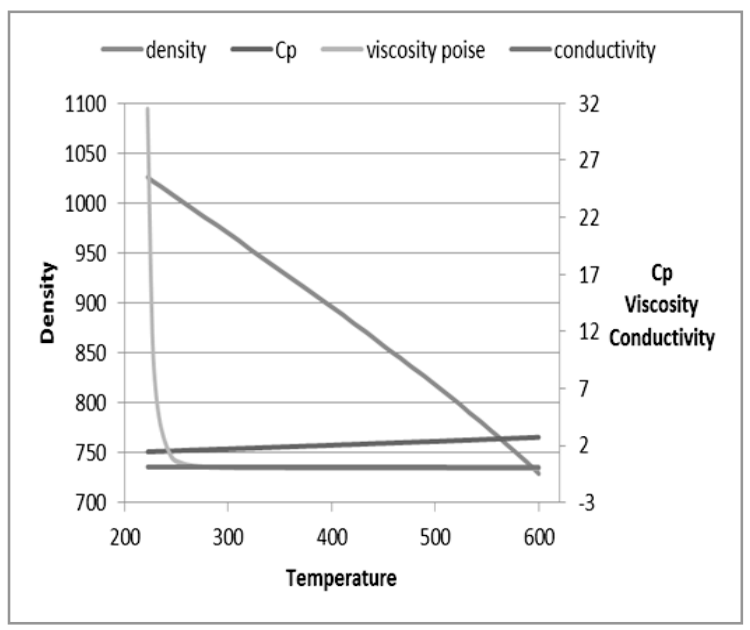

Therminol 59

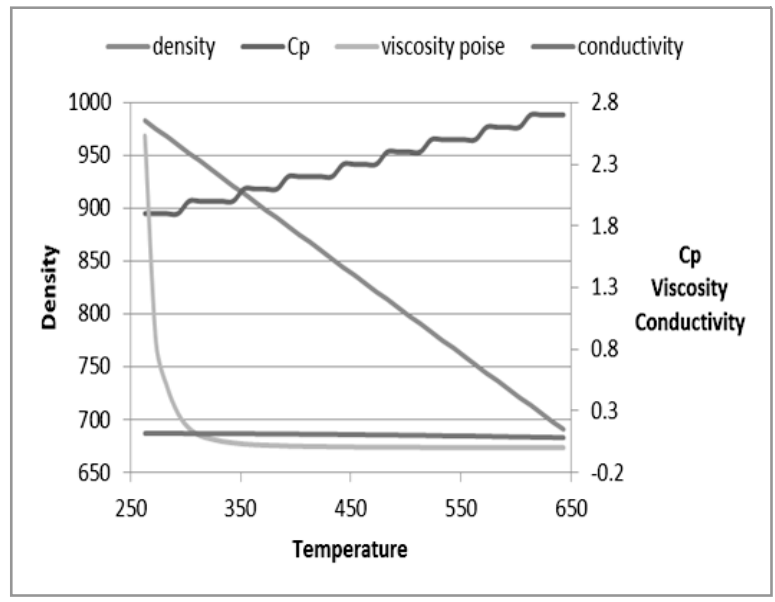

Paratherm HR

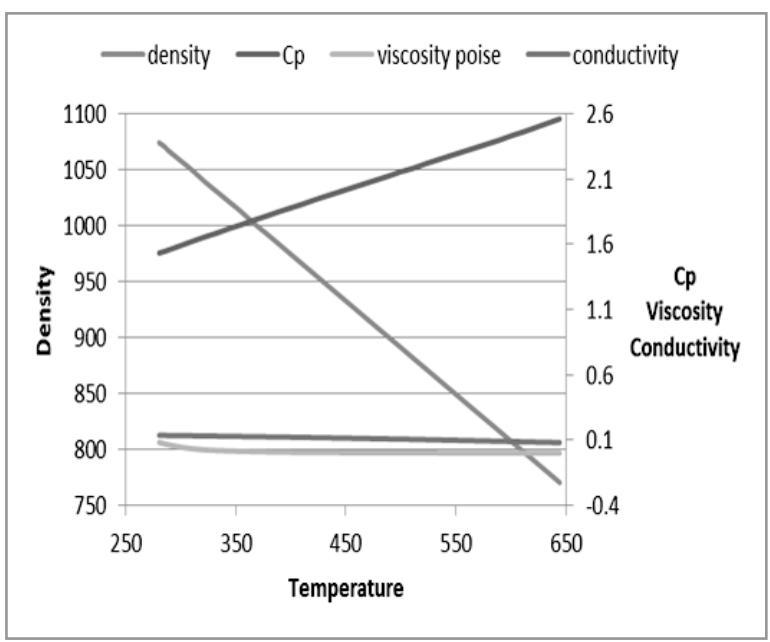

Xceltherm LV

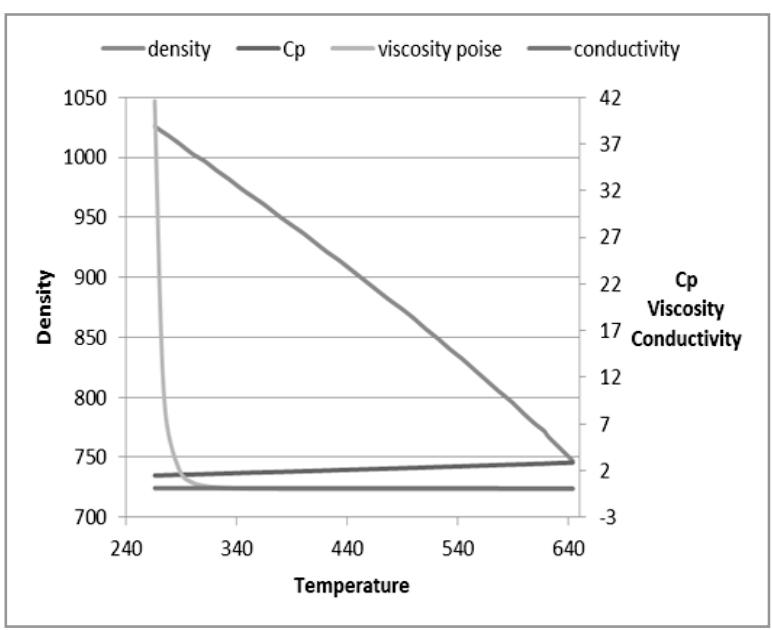

Therminol 66 


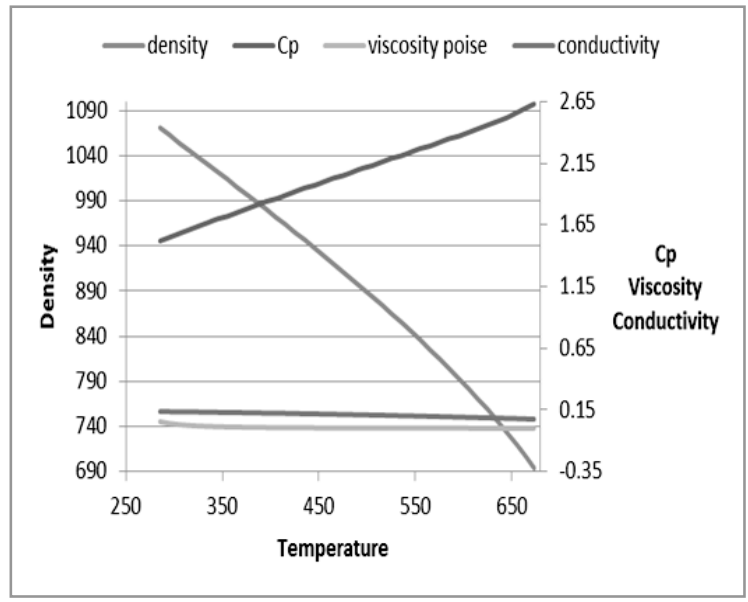

Therminol VP1

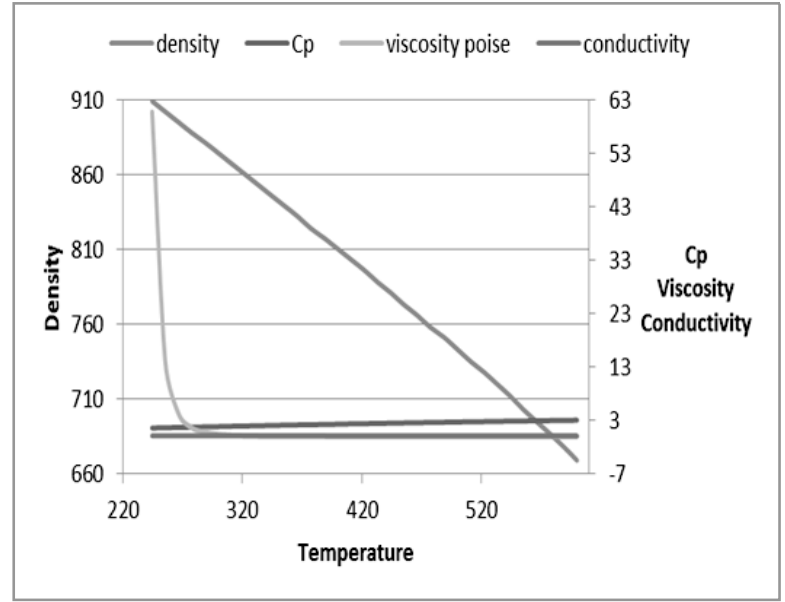

Therminol XP

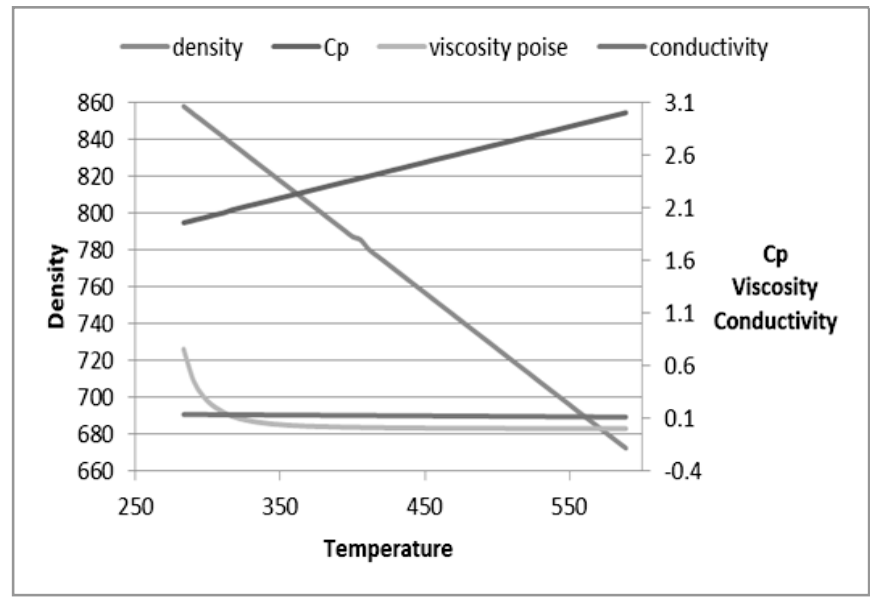

Xceltherm 600

Figure 19. Thermal fluids property. 
Table 10. SN 150 group II specifications.

\begin{tabular}{|c|c|c|c|}
\hline \multicolumn{2}{|c|}{ Parameters } & ASTM & $150 N$ \\
\hline \multicolumn{2}{|c|}{ Specific Gravity, $15 / 4^{\circ} \mathrm{C}$} & D1298 & 0.8666 \\
\hline \multicolumn{2}{|c|}{ Colour, Say bolt } & D1500 & L1.0 \\
\hline \multirow{2}{*}{ Kinetic Viscosity } & @40,cSt & D445 & 30.14 \\
\hline & @ $100, \mathrm{cSt}$ & & 5.189 \\
\hline \multicolumn{2}{|c|}{ Viscosity Index } & D2270 & 101 \\
\hline \multicolumn{2}{|c|}{ Flash Point, ${ }^{\circ} \mathrm{C}(\mathrm{COC})$} & D92 & 212 \\
\hline \multicolumn{2}{|c|}{ Pour Point, ${ }^{\circ} \mathrm{C}$} & D97 & -12.5 \\
\hline \multicolumn{2}{|c|}{ Sulphur Content, wt ppm } & D5453 & $<100$ \\
\hline \multicolumn{2}{|c|}{ Carbon Residue(CCR), wt $\%$} & D189 & 0.04 \\
\hline \multicolumn{2}{|c|}{ Copper Corrosion, $100^{\circ} \mathrm{C} / 3 \mathrm{hr}$} & D130 & $1 \mathrm{a}$ \\
\hline \multicolumn{2}{|c|}{ TAN, $\mathrm{mgKOH} / \mathrm{g}$} & D974 & $<0.01$ \\
\hline \multirow{3}{*}{ Ring Analysis, } & wt $\% \mathrm{CA}$ & & 1.8 \\
\hline & $\mathrm{wt} \% \mathrm{CN}$ & D3238 & 32.1 \\
\hline & $\mathrm{wt} \% \mathrm{CP}$ & & 66.1 \\
\hline \multicolumn{2}{|c|}{ Aniline Point, ${ }^{\circ} \mathrm{C}$} & D611 & 107.1 \\
\hline
\end{tabular}

Table 11. Simulation of a PTC system at different fluids ambient temperature $300 \mathrm{~K}$.

\begin{tabular}{|c|c|c|c|}
\hline Fluid Type & $\mathbf{T}_{\mathbf{f o}}{ }^{\prime} \mathbf{K}^{\prime}$ & Efficiency & Delta T 'K' \\
\hline Dowtherm Q & 351.2 & 0.2821 & 51.2 \\
\hline Dowtherm A & 359 & 0.3087 & 59 \\
\hline Dowtherm G & 355.6 & 0.2898 & 55.6 \\
\hline Dowtherm J & 350.2 & 0.3046 & 50.2 \\
\hline Dowtherm MX1 & 352.9 & 0.2849 & 52.9 \\
\hline Dowtherm RP & 355.3 & 0.2983 & 55.3 \\
\hline Therminol 59 & 350.8 & 0.2839 & 50.8 \\
\hline Therminol 66 & 353 & 0.27 & 53 \\
\hline Therminol Vp1 & 359.7 & 0.308 & 59.7 \\
\hline Therminol XP & 347.4 & 0.2915 & 47.4 \\
\hline Xceltherm HT & 358.2 & 0.2764 & 58.2 \\
\hline Xceltherm 600 & 396.6 & 0.3122 & 96.6 \\
\hline Xceltherm LV & 397.6 & 0.3073 & 97.6 \\
\hline Marlotherm & 356.5 & 0.2964 & 56.5 \\
\hline Paratherm GLT & 352.2 & 0.3309 & 52.2 \\
\hline Paratherm_HE & 348.4 & 0.305 & 48.4 \\
\hline Paratherm_HR & 344.5 & 0.2811 & 44.5 \\
\hline Paratherm_HF & 340.8 & 0.2543 & 40.8 \\
\hline Syltherm 800 & 357.6 & 0.3006 & 57.6 \\
\hline
\end{tabular}


SN 150 group II is the thermal oil used for the experimentations, and Table 10 represents some of its properties (M. I. Roldan et al., 2013). The mathematical model generated on EES was simulated for the selected nineteen thermal oils. The HTF outlet temperature and efficiency were obtained for each of the oils. The simulation results of a PTC system at different fluids are shown in Table 11.

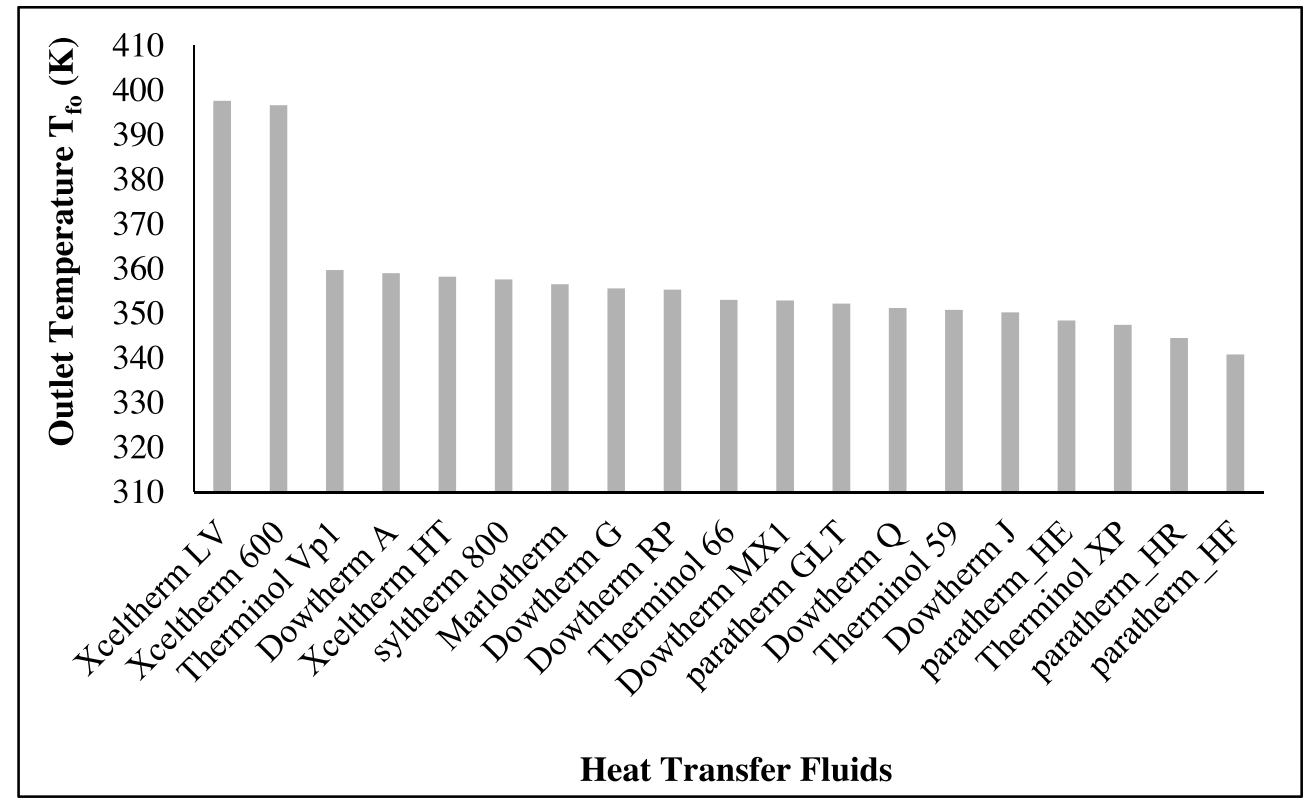

Figure 20. Comparison of outlet temperature of different thermal fluid.

From Figure 20, it was found that, in the PTC model, the fluids gaining the maximum temperature are Xceltherm LV and Xceltherm 600 increasing to 397.6 and 396.6, respectively. The remaining fluids have outlet temperature in the range of 359.7 and 340.8. The Paratherm GLT has the highest efficiency of 0.3309 as shown in Figure 21.

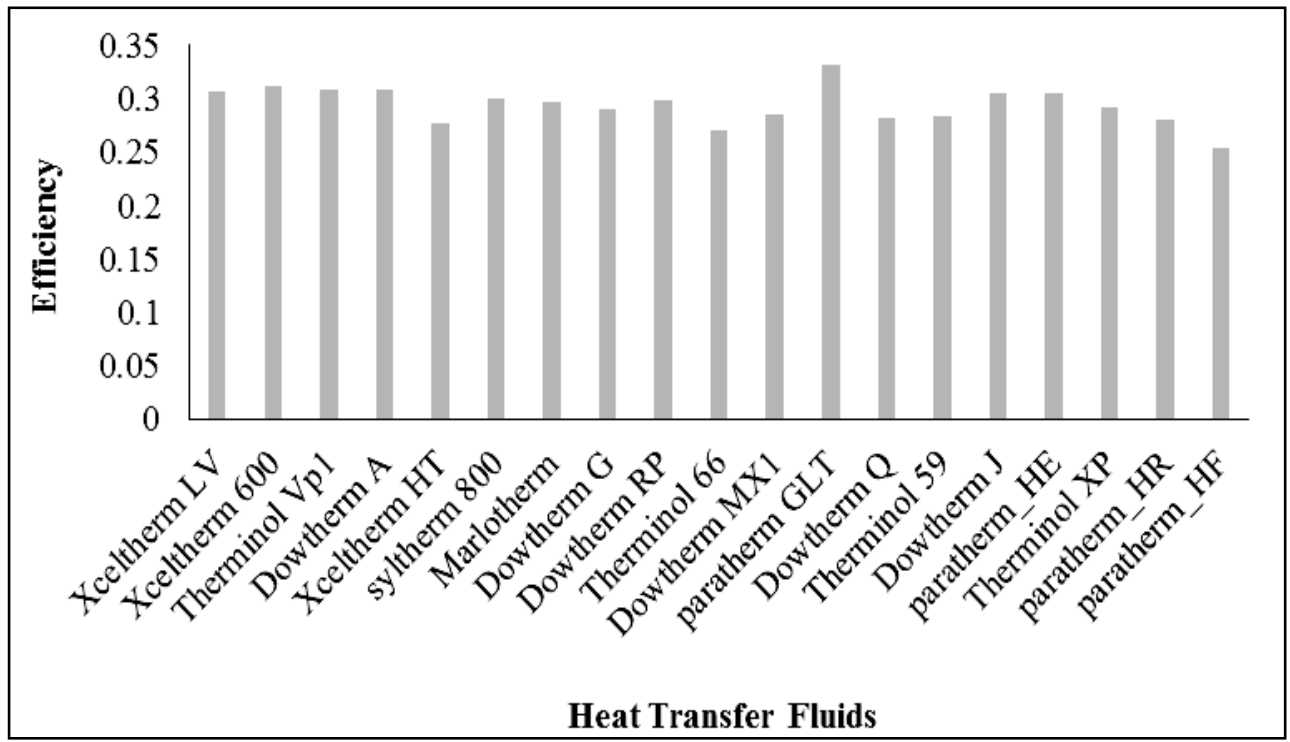

Figure 21. Efficiency effect on different thermal fluids. 


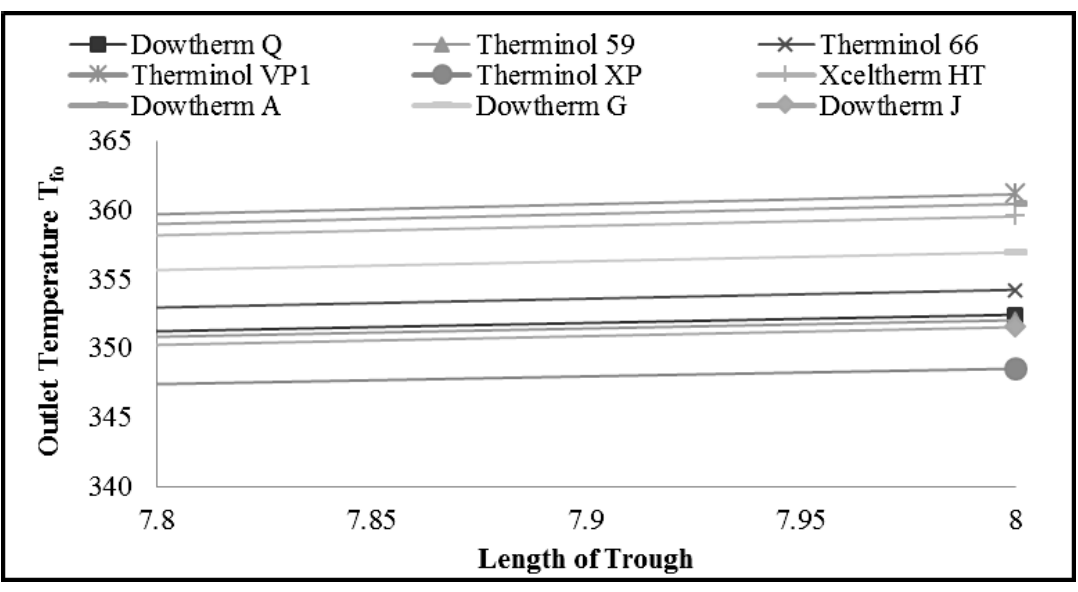

Figure 22. Temperature profile of the different thermal fluids.

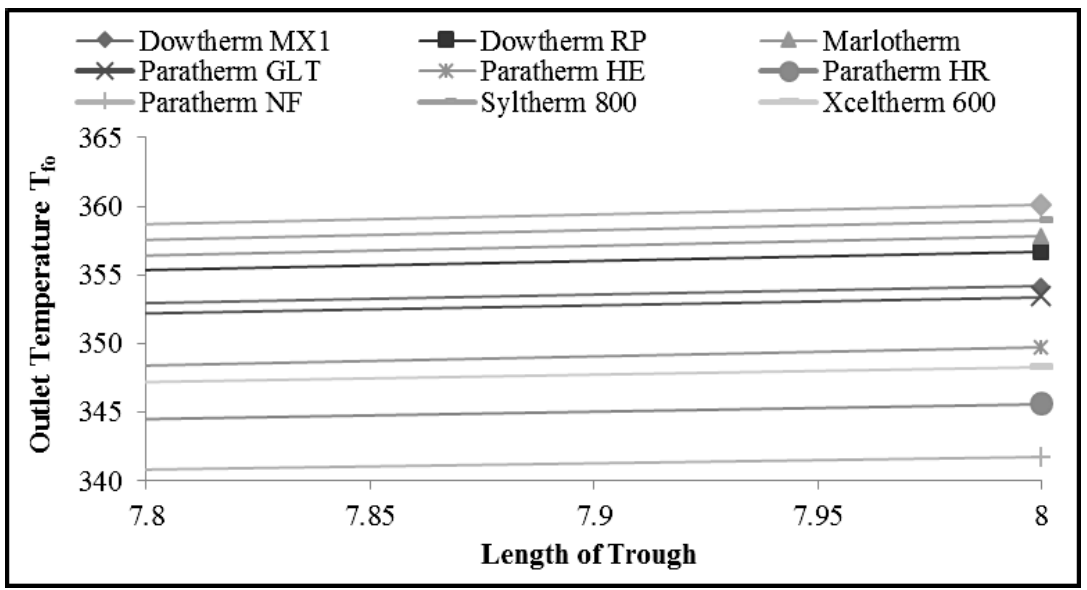

Figure 23. Temperature profile of the remaining thermal fluids.

Figures 22 and 23 portrait that when the temperature increases, the length of PTC also increases. It was found that no big change occurs in the slope for all fluids. The slopes lie between 5.508 and 7.8411 as presented in Table 12 .

Table 12. Temperature profile slopes of different thermal fluids.

\begin{tabular}{|c|c|c|c|}
\hline Fluid & Slope & Fluid & Slope \\
\hline Therminol VP1 & 7.8411 & Paratherm GLT & 6.9744 \\
\hline Dowtherm A & 7.7507 & Dowtherm Q & 6.7682 \\
\hline Xceltherm LV & 7.7226 & Therminol 59 & 6.724 \\
\hline Xceltherm HT & 7.6429 & Dowtherm J & 6.6602 \\
\hline Syltherm 800 & 7.5851 & Paratherm HE & 6.362 \\
\hline Marlotherm & 7.4317 & Therminol XP & 6.2822 \\
\hline Dowtherm G & 7.3248 & Xceltherm 600 & 6.266 \\
\hline Dowtherm RP & 7.2951 & Paratherm HR & 5.9447 \\
\hline Dowtherm MX1 & 6.9911 & Paratherm NF & 5.5087 \\
\hline
\end{tabular}


Figures 24 and 25 show the pressure drop across the length of PTC, and a profile curve was produced. Fluids with low-pressure drop are usually more desired.

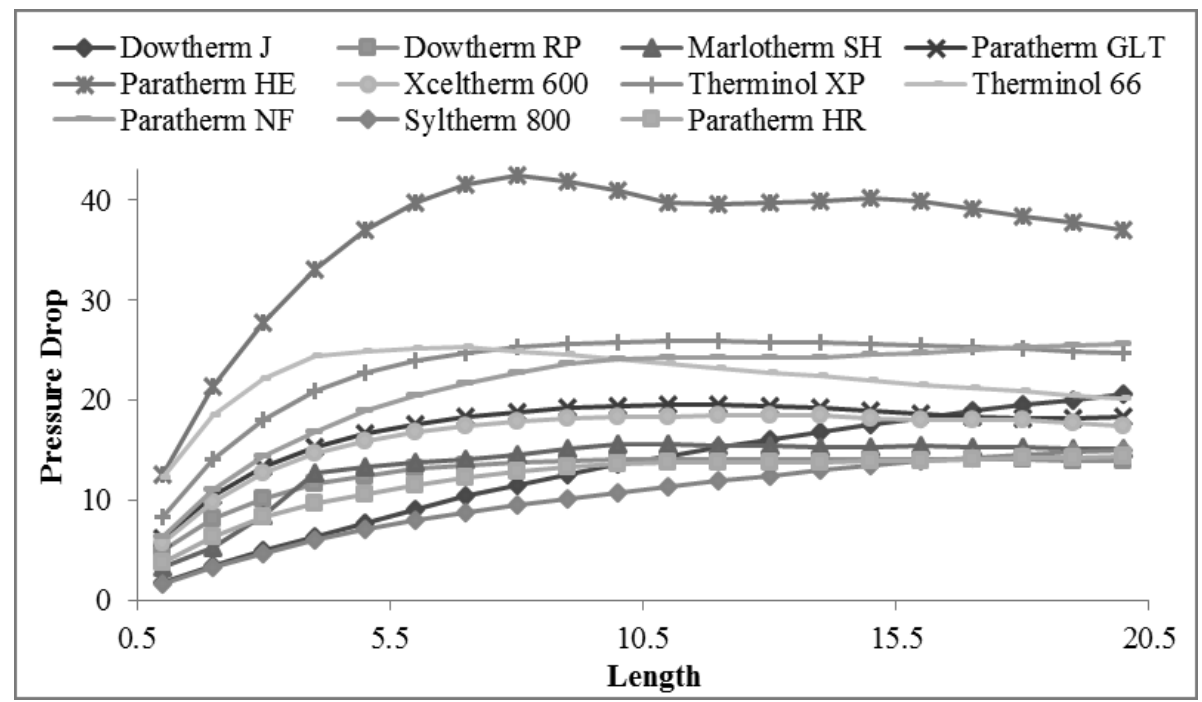

Figure 24. Effect of length on pressure drop of different thermal fluids.

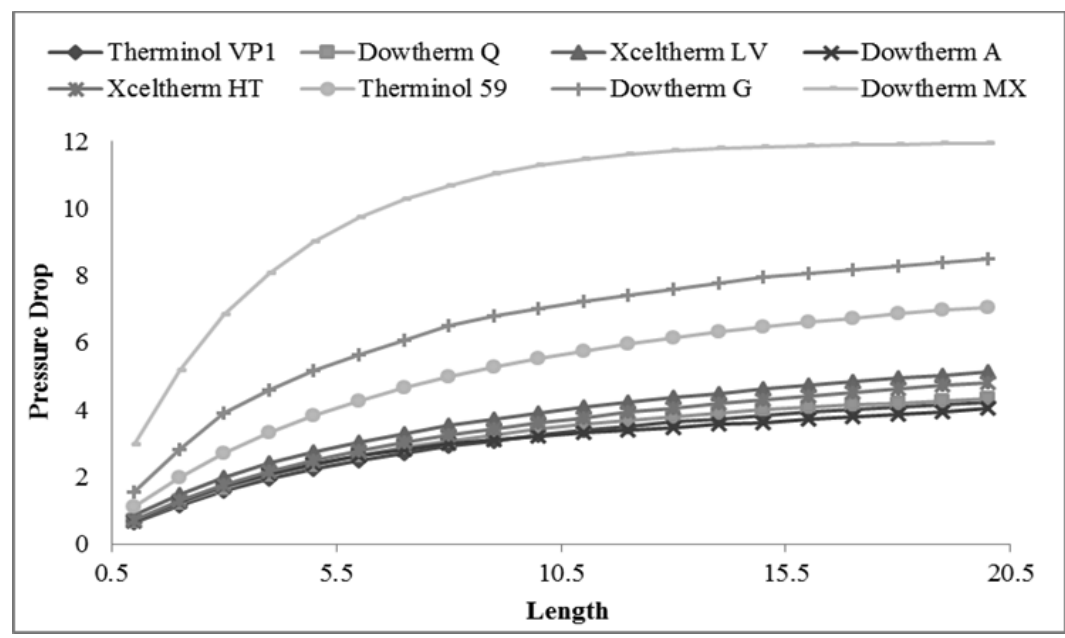

Figure 25. Effect of length on pressure drop of remaining thermal fluids.

\section{CONCLUSION}

The aim of the project has been accomplished, and concentrated solar plant (CSP) has been successfully developed. The model is recommended for heat transfer applications simulated with nineteen different thermal fluids. The correlations developed are in great concurrence with both the literature and experimental results. The comparison of practical results and theoretical model for water solved through EES are found in good acceptance. From the findings, it was seen that when temperature rises, the length of PTC also increased, and a slight change occurs in the slope for all fluids. The pressure drop across the length of PTC was observed, and fluids with low-pressure drop are usually more desired. It is concluded that technologies are a reliable alternative to the conventional plants. Since the domestic and pilot-scale plant proves its effectiveness and potential, steps must be taken for large-scale production. 


\section{ACKNOWLEDGMENT}

The authors would like to acknowledge the Department of Chemical Engineering and Department of Polymer and Petrochemical Engineering, NED University of Engineering \& Technology, Karachi, Pakistan, for supporting this research work.

\section{NOMENCLATURE}

\begin{tabular}{|c|c|c|}
\hline Symbol & Description & Units \\
\hline$\alpha_{a b s}$ & Absorber or coating absorptivity & - \\
\hline$\alpha_{e n v}$ & Envelope absorptivity & - \\
\hline$C$ & The concentration ratio of PTC & - \\
\hline$C p_{f}$ & Heat capacity of HTF & $\mathrm{J} / \mathrm{K}$ \\
\hline $\mathrm{dia}_{2}$ & Diameter of inside absorber pipe & $\mathrm{m}$ \\
\hline$\Delta d i a_{23}$ & Difference between absorber inner and outer diameter (absorber thickness) & - \\
\hline$\Delta d i a_{34}$ & Difference between absorber outer and envelope inner diameter & - \\
\hline$\Delta d i a_{45}$ & Difference between envelope inner and outer diameter (thickness of the envelope) & - \\
\hline$\Delta$ & Difference between the inlet and exit HTF temperature & - \\
\hline$\epsilon_{1}$ & Shadowing of bellows, shielding, support: an estimate of effective optical efficiency & - \\
\hline$\epsilon_{2}$ & Tracking error: an estimate of effective optical efficiency & - \\
\hline$\epsilon_{3}$ & Geometry error/mirror alignment error: an estimate of effective optical efficiency & - \\
\hline$\epsilon_{4}$ & Dirt on mirror & - \\
\hline$\epsilon_{5}$ & Dirt on Collector & - \\
\hline$\epsilon_{6}$ & Unaccounted errors: an estimate of effective optical efficiency & - \\
\hline$\epsilon_{a b s}$ & Emittance of coating or absorber & - \\
\hline$\epsilon_{e n v}$ & Emittance of envelope & - \\
\hline$h_{21}$ & Fluid convective heat transfer coefficient & $\mathrm{W} / \mathrm{m}^{2} \mathrm{~K}$ \\
\hline$h_{56}$ & Wind convection heat transfer coefficient & $\mathrm{W} / \mathrm{m}^{2} \mathrm{~K}$ \\
\hline$h_{34}$ & Envelope gas convection heat transfer coefficient & $\mathrm{W} / \mathrm{m}^{2} \mathrm{~K}$ \\
\hline$k_{a b s}$ & Thermal conductivity of absorber & $\mathrm{W} / \mathrm{m} \mathrm{K}$ \\
\hline$k_{e n v}$ & Thermal conductivity of envelope & $\mathrm{W} / \mathrm{m} \mathrm{K}$ \\
\hline$K_{\text {inc }}$ & Incident angle modifier & - \\
\hline$k_{f}$ & Thermal conductivity of HTF & $\mathrm{W} / \mathrm{m} \mathrm{K}$ \\
\hline$L$ & Length of PTC & $\mathrm{m}$ \\
\hline$\dot{m}$ & The mass flow rate of HTF & $\mathrm{kg} / \mathrm{s}$ \\
\hline$\eta_{o}$ & Reflectivity & - \\
\hline$\eta$ & Efficiency & - \\
\hline$\eta_{e n v}$ & The efficiency of the envelope & - \\
\hline$\eta_{a b s}$ & The efficiency of the absorber & - \\
\hline$\rho_{c l}$ & Clean mirror reflectance: an estimate of effective optical efficiency & - \\
\hline$\rho_{f}$ & Density of HTF & $\mathrm{kg} / \mathrm{m}^{3}$ \\
\hline$q_{d d}$ & Solar radiations & $\mathrm{W} / \mathrm{m}^{2}$ \\
\hline
\end{tabular}




\begin{tabular}{|c|l|c|}
\hline$R e_{f}$ & Reynolds number of HTF & - \\
\hline$\sigma$ & Stephan Boltzmann constant & - \\
\hline$T_{f i}$ & The inlet temperature of HTF & $\mathrm{K}$ \\
\hline$T_{f o}$ & The exit temperature of the HTF & $\mathrm{K}$ \\
\hline$\tau_{e n v}$ & The transmittance of the glass envelope & - \\
\hline$T_{1}$ & Mean bulk temp & $\mathrm{K}$ \\
\hline$T_{2}$ & Inside absorber pipe temperature & $\mathrm{K}$ \\
\hline$T_{3}$ & Outside absorber pipe temperature & $\mathrm{K}$ \\
\hline$T_{4}$ & Inside glass tube temperature & $\mathrm{K}$ \\
\hline$T_{5}$ & Outside glass tube temperature & $\mathrm{K}$ \\
\hline$T_{6}$ & Ambient temperature & $\mathrm{K}$ \\
\hline$T_{7}$ & Sky temperature & $\mathrm{K}$ \\
\hline$\theta$ & Solar incidence angle & degree \\
\hline$\mu_{f}$ & viscosity of HTF & $\mathrm{kg} / \mathrm{m}-\mathrm{s}$ \\
\hline
\end{tabular}

\section{REFERENCES}

Agyenim, F., Hewitt, N., Eames, P. \& Smyth, M. 2010. A review of materials, heat transfer and phase change problem formulation for latent heat thermal energy storage systems (LHTESS). Renewable and Sustainable Energy Reviews. 14: 615-628.

Barlev, D., Vidu, R. \& Stroeve, P. 2011. Innovation in concentrated solar power. Solar Energy Materials \& Solar Cells. 95: 27032725.

Benoit, H., Spreafico, L., Gauthier, D. \& Flamant, G. 2016. Review of heat transfer fluids in tube-receivers used in concentrating solar thermal systems: Properties and heat transfer coefficient. Renewable and Sustainable Energy Reviews. 55: 298-315.

Cheng, Z.D., He, Y.L., Xiao, J., Tao, Y.B. \& Xu, R.J. 2010. Three-dimensional numerical study of heat transfer characteristics in the receiver tube of parabolic trough solar collector. International Communications in Heat and Mass Transfer. 37: 782787.

Chu, S. \& Majumdar, A. 2012. Opportunities and challenges for a sustainable energy future. Nature. 488(7411): 294-303.

Fenot, M., Bertin, Y., Dorignac, E. \& Lalizel, G. 2011. A review of heat transfer between concentric rotating cylinders with or without axial flow. International Journal of Thermal Sciences. 50: 1138-1155.

Garcia, A.F., Zarza, E., Valenzuela, L. \& M.Perez. 2010. Parabolic-trough solar collectors and their applications. Renewable and Sustainable Energy Reviews. 14: 1695-1721.

Godson, L., Raja, B., Lal, D.M. \& Wongwises, S. 2010. Enhancement of heat transfer using nanofluids-An overview. Renewable and Sustainable Energy Reviews. 14: 629-641.

Hachicha, A.A., Rodríguez, I., Capdevila, R. \& Oliva, A. 2013. Heat transfer analysis and numerical simulation of a parabolic trough solar collector. Applied Energy. 111: 581-592.

Ho, C.K., Khalsa, S.S. \& Kolb, G.J. 2011. Methods for probabilistic modeling of concentrating solar power plants. Solar Energy. 85: 669-675.

Ho, C.K. \& Iverson, B.D. 2014. Review of high-temperature central receiver designs for concentrating solar power. Renewable and Sustainable Energy Reviews. 29: 835-846.

Hosseini, M.J., Rahimi, M. \& Bahrampoury, R. 2014. Experimental and computational evolution of a shell and tube heat exchanger as a PCM thermal storage system. International Communications in Heat and Mass Transfer. 50: 128-136.

Kuravi, S., Trahan, J., Goswami, D.Y., Rahman, M.M. \& Stefanakos, E.K. 2013. Thermal energy storage technologies and systems for concentrating solar power plants. Progress in Energy and Combustion Science. 39: 285-319.

Lakew, A.A. \& Bolland, O. 2010. Working fluids for low-temperature heat source. Applied Thermal Engineering. 30: 1262-1268. 
Montes, M.J., Abanades, A., Martınez-Val, J.M. \& Valdes, M. 2009. Solar multiple optimization for a solar-only thermal power plant, using oil as heat transfer fluid in the parabolic trough collectors. Solar Energy. 83: 2165-2176.

Ouagued, M. \& Khellaf, A. 2012. Simulation of the Temperature and Heat Gain by Solar Parabolic Trough Collector in Algeria. International Journal of Physical and Mathematical Sciences. 6(7): 747-752.

Padilla, R.V., Demirkaya, G., Goswamic, D.Y., Stefanakos, E. \& Rahman, M.M. 2011. Heat transfer analysis of parabolic trough solar receiver. Applied Energy. 88: 5097-5110.

Pawar, S.S. \& Sunnapwar, V.K. 2013. Experimental studies on heat transfer to Newtonian and non-Newtonian fluids in helical coils with laminar and turbulent flo. Experimental Thermal and Fluid Science. 44: 792-804.

Philip, J. \& Shima, P.D. 2012. Thermal properties of nanofluids. Advances in colloid and interface science. 183-184: 30-45.

Price, H., Lupfert, E., Kearney, D., Zarza, E. \& Mahoney, R. 2002. Advances in Parabolic Trough Solar Power Technology. Journal of Solar Energy Engineering. 124: 109-125.

Roesle, M., Good, P., Coskun, V. \& Steinfeld, A. 2012. Analysis of Conduction Heat Loss From a Parabolic Trough Solar Receiver with Active Vacuum by Direct Simulation Monte Carlo. Numerical Heat Transfer, Part A. 62: 432-444.

Roldan, M.I., Valenzuela, L. \& Zarza, E. 2013. Thermal analysis of solar receiver pipes with superheated steam. Applied Energy. 103: $73-84$.

Vignarooban, K., Xu, X., Arvay, A., Hsua, K. \& Kannana, A.M. 2015. Heat transfer fluids for concentrating solar power systems - A review. Applied Energy. 146: 383-396.

Zaversky, F., Garcia-Barberena, J., Sanchez, M. \& Astrain, D. 2012. Probabilistic modeling of a parabolic trough collector power plant - An uncertainty and sensitivity analysis. Solar Energy. 86: 2128-2139.

Zhang, H.L., Baeyens, J., Degreve, J. \& Caceres, G. 2013. Concentrated solar power plants: Review and design methodology. Renewable and Sustainable Energy Reviews. 22: 466-481. 